\title{
$\$$ Research Square \\ Cost Effective Design of RC Building Frame Employing Unified Particle Swarm Optimization
}

Payel Chaudhuri ( $\triangle$ payelce@gmail.com )

Indian Institue of Technology, Kharagpur https://orcid.org/0000-0003-2214-9554

\section{Swarup Barman}

Indian Institute of Technology Kharagpur

\section{Damodar Maity}

Indian Institute of Technology Kharagpur

\section{Dipak Kumar Maiti}

Indian Institute of Technology Kharagpur

\section{Research Article}

Keywords: cost effective design, unified particle swarm optimization, STAAD Pro, RC building frame, wind load, seismic load.

Posted Date: April 28th, 2021

DOI: https://doi.org/10.21203/rs.3.rs-227713/v1

License: (1) (1) This work is licensed under a Creative Commons Attribution 4.0 International License. Read Full License 


\title{
Cost effective design of RC building frame employing unified particle swarm optimization
}

\author{
Payel Chaudhuri ${ }^{1}$, Swarup K. Barman ${ }^{2}$, Damodar Maity ${ }^{1}$, Dipak K. Maiti ${ }^{2}$ \\ ${ }^{1}$ Civil Engineering Department, Indian Institute of Technology, Kharagpur -721302, India, \\ payelce@gmail.com \\ ${ }^{2}$ Aerospace Engineering Department, Indian Institute of Technology, Kharagpur -721302, \\ India.
}

\section{ABSTRACT}

Present paper deals with the cost effective design of reinforced concrete building frame employing unified particle swarm optimization (UPSO). Two building frames with G+8 stories and $\mathrm{G}+10$ stories have been adopted to demonstrate the effectiveness of the present algorithm. Effect of seismic loads and wind load have been considered as per Indian Standard (IS) 1893 (Part-I) and IS 875 (Part-III) respectively. Analysis of the frames has been carried out in STAAD Pro software. The design loads for all the beams and columns obtained from STAAD Pro have been given as input of the optimization algorithm. Next, cost optimization of all beams and columns have been carried out in MATLAB environment using UPSO, considering the safety and serviceability criteria mentioned in IS 456. Cost of formwork, concrete and reinforcement have been considered to calculate the total cost. Reinforcement of beams and columns has been calculated with consideration for curtailment and feasibility of laying the reinforcement bars during actual construction. The numerical analysis ensures the accuracy of the developed algorithm in providing the cost optimized design of RC building frames considering safety, serviceability and constructional feasibilities.Further, Monte Carlo simulations performed on the numerical results, proved the consistency and robustness of the developed algorithm. Thus, the present algorithm is capable of giving a cost effective design of RC building frame, which can be adopted directly in construction site without making any changes. 
Key words: cost effective design, unified particle swarm optimization, STAAD Pro, RC building frame, wind load, seismic load.

\section{Introduction}

Reinforced concrete is a dominant material for constructing various civil engineering structures due to its high compressive strength, durability and resistance to damage from fire and water. Conventional trial and error based design of RC structures is based on only safety criteria, and requires excessive materials. Thus construction costs of building increases. So, increase in use of reinforcement concrete comes with the demand for economical design. Thus, from last few decades, researchers have proposed different method for cost optimization of RC frames. Increase in computational power of computers has enhanced the willfulness of such attempts drastically. Main challenge in optimizing the RC structures are number of optimizing variables in comparison with the optimal design of steel structures, where only material is considered for entire structures and cost of the entire structure is proportional to weight of that material. On the other hand, cost of RC structures consist of cost of concrete, cost of steel reinforcement and cost of formworks. Their unit costs differ from each other. Their inter-relations are not simple, because any two of them change significantly with slight changes in the quantity of the third factor. This in turn changes the total cost of RC frame to a great extent. Thus, the actual problem comes to finding appropriate combination of values for three aforementioned components of costs without violating the safety requirements so that the total cost becomes minimum. Again, RC sections are cast in situ. So, while designing cost effective sections, size of the sections and reinforcement detailing should be provided to meet the specific demands from architectural and construction point of view. Thus, presence of all these factors along with constraints regarding strength, serviceability, architectural demands and easiness of construction make cost optimization of real life RC structures a highly cumbersome task. However, in the same time an algorithm to optimize the cost of a RC building frame satisfying all the necessary criteria will be a valuable tool to the design practitioner.

Despite all these challenges many researchers have tried to find cost optimize designs of RC building components. Milajić et al. [1] reviewed various methods available in literatures for optimal design of reinforced concrete structure. They focused on the problems of these existing methodologies, such as: gap between the theory and practice in the field, lack of universal criteria and standard benchmark problem etc.Also, when ones talks about of cost 
optimized design of a complete RC building project, it includes optimizing the topology of the building, material costs of the building components, reinforcement distribution, cost of shuttering, labor cost maintaining all the safety guidelines of competent authority.

Topology optimization of building means finding out optimum layout of the building for a particular project. Topology optimization is avery popular and common term in steel structures, where topology of truss is optimized to achieve cost optimum design [2]. However, researchers also tried to implemented the concept of topology optimization also in case of concrete structures by various means, such as windowed evolutionary structural optimization (WESO) [3], plastic design layout optimization technique [4], dynamic programming utilizing genetic algorithm (GA) based multi objective optimization [5]. Apart from that, Zegard et al. [6] have implemented three different methods of topology design optimization in building engineering. However, in real project topology is not decided solely based oncost only. There are other deciding factor such as utility of the building, aesthetic beauty or client's wish. Labor cost depend on the location of the construction and days required to finish the construction. This can be managed with proper constructionmanagement and planning strategies like Critical Path Method (CPM) and Project Evaluation and Review Technique (PERT). Thus, present study is focused on the optimizing the design of the structural components of a building frame.

Structural components, such as, beams, columns, slab and foundation contribute most in the total cost of a project. Thus, cost optimum design of structural components are of utmost important for minimizing the project cost. Cost optimum design of RC beams have been attempted by researchers utilizing various methods, simplex and Lagrangian optimization method [7], geometric programming [8], GA based algorithm [9, 10], polynomial optimization technique [11], simulated annealing [12], random search technique (RST) [13], charged system search (CSS) [14]. Cost optimum design of T-beams [15]andCost optimum design RC columns [7, 16, 17] also have been attempted. Apart from beam and column optimization, design of reinforced concrete (RC) flat slabs have also been optimized by Aldwaik and Adeli [18] using Neural dynamic model for Adeli and Park (NDAP) [19], Design optimization of RC foundation has been performed by Chaudhuri and Maity [20]. Besides these individual structural components researchers have also tried to optimize the beam-column frames in terms of weight [21], in terms of cost [22-29]. All these studies regarding design optimization of $\mathrm{RC}$ building components or frames are conformed to the 
guidelines decided by the various standards of different countries such as Indian standard (IS 456)[7,11, 20, 26], American standard (ACI 318, ASCE7)[13,17, 21-25, 28, 29], European standard (Eurocode 2) [15,27] and Australian standard (AS 3600) [14], Brazilian standard (NBR 6118)[12]. Apart from these, RazmaraShooli et al. [30] have proposed a GA-PSO based algorithm for performance-based design optimization of a special moment-resisting frames based on guidelines provided by American standards (ATC-40, FEMA 356, ASCE-7 and ASCE-41).In these literatures the researchers used geometry of beam, column, amount of reinforcement, cost of material and shuttering as their optimization variable.In the problems regarding optimized design of RC components, optimizing the distribution of reinforcement are also an important issue $[31,32]$.

While solving any optimization problems choosing proper optimization techniques is utmost important, every optimization techniques have their strengths and weaknesses. In this regard, it is important to have an idea about the optimization techniques used by the predecessors to solve a particular class of problems. The cost optimization design problems of RC frames have been tackled by the researchers by using various optimization techniques. Few of them have already been discussed earlier in this section. However, reviews of the optimization algorithms used by researchers have been presented in Table 1 for clarity.

Thus, the key points, which have been observed from the above literature are as follows:

i) Literature studying the cost-optimum design of RC building are quite less in number.

ii) Most of the literatures are focused on the optimization of only a particular member (beam or column), and reinforcement detailing pattern of beam or column sections.

iii) Also, no algorithm from above literature have been tested for large scale multistorey building frame to provide cost optimized design accompanied by construction friendly reinforcement detailing.

iv) Usage of optimization techniques in this field is also very less compared to other fields like structural health monitoring, travelling salesman problems, water resource etc. 
Apart from above points another important issue is the shortcomings of commercial design software. Although, design performed in the software is correct in term of safety criteria, they provide the reinforcement amount in terms area instead construction friendly reinforcement detailing. Thus, the method developed in the present studyaims towards alleviate these shortcomings. Also Unified Particle Swarm Optimization has not been used asa cost optimization method for multistory building design in the previous studies, although it has been used very effectively in cost optimization of RC foundation [20], damage detection problems [33-38], magnetoencephalography problem [39] etc. Hence, UPSO have been found to the appropriate optimization method for multistory building design and cost optimization. Thus, main objective of the present paper is to develop cost-optimized design algorithm for RC frames following the safety and serviceability requirements of IS 456 [40] employing UPSO. Efficiency of the algorithm has been shown using two building frames $(\mathrm{G}+8$, and $\mathrm{G}+10)$ of different planner configurations. Effects of seismic and wind load also have been considered. Optimization has been performed based on minimum cost rather than minimum weight, as the considered building frames are not high-rise (Prakash et al. [7]). Final optimized sections and reinforcement details obtained from the present algorithm can be used without altering in the actual site during construction phase.The efficiency of the developed design optimization algorithm has been investigated using Monte Carlo simulation. Monte Carlo method estimates the probability of favorablesolution of the developed optimization algorithm when a large number of experiments are carried out for cost optimization of both the buildings. This consequently evaluates the robustness of the developed algorithm in case of huge number of experiments and different types of buildings.

\section{Mathematical formulation}

An UPSO based algorithm has been developed in the present study to obtain cost effective design of the multi-storeyed reinforcement concrete frame. Details of structural analysis, design criteria, optimization algorithm, objective functions have been discussed in a brief manner in this section.

\subsection{Structural analysis}

In general building frames are subjected to gravity load (dead load (DL) and live load (LL)), wind load (WL) and seismic load (SL). Designers use all these loads in various combinations to calculate design forces such as axial loads, bending moments and shear 
forces for beams and columns. The moments, shear forces and axial loads for the critical load combination are used to design the beams and columns of the building frames. Detail procedure for analysis of building frames under aforementioned loads is mentioned briefly in the subsequent sections.

\subsubsection{Gravity loads}

Gravity loads consist of dead load and live load. Dead load of different components of a building can be considered as per IS 875 (Part I) [41]. Dead loads constitute of the following loads.

1. Self-weight of beams and columns.

2. Self-weight of internal and external wall and parapet wall.

3. Self-weight of floor slabs.

4. Dead load coming from floor finish and plastering

Any temporary or transient loads which act on the building can be defined as live loads. People, furniture, vehicles, and almost everything else that can be moved throughout a building come under live loads. Live loads can be provided to any structural element (floors, columns, beams, even roofs). Appropriate amount and type of live load can be decided based on the specification given on IS 875 (Part II) [42].

\subsubsection{Wind loads}

Wind load should be considered for designing a multi-storey building frame.The nature of flow of wind past a body resting on a surface depends on the conditions of the surface, the shape of the body, its height, velocity of wind flow and many other factors [43]. IS 875 (Part III) [44] contains the guidelines for considering the effects of wind on a multistorey building. The shape of wind load velocity profile is similar to boundary layer flow profile.A typical velocity profile of wind load considered for analysis has been shown in Fig. 1. The dotted line represents boundary layer. In general velocity is zero at the ground and increases up to the boundary layer. Beyond boundary layer wind velocity does not changes with height. As the wind travel in upstream direction through a particular terrain, the wind profile changes and velocity and height of boundary layer increases. The distance travelled by a wind profile 
181

182

183

184

185

186

187

188

189

190

191

192

193

194

195

196

197

198

199

200

on a particular terrain is called fetch length, i.e. $\mathrm{x}_{1}$ and $\mathrm{x}_{2}$ in Fig. 1. Upward penetration of the velocity profile at any fetch length is called developed height, i.e., $h_{1}$ and $h_{2}$ in Fig.1.Developed height increases up to gradient height, where velocity become maximum. After that even if wind travel upstream direction velocity profile remain unchanged. At this point it can said that velocity profile is fully developed for that particular terrain. In case of wind analysis of a structures generally it is assumed that wind profile is fully developed before hitting the structure. The values of a fully developed velocity profile depends on the terrain category. As the terrain category becomes rougher, gradient height increases. IS 875 (Part III) [44] have provided the multiplier for velocity profile for each terrain category.

Initially wind analysis of any structure starts with selecting proper basic wind speed $V_{b}$ depending on the location of the structure. The design wind speed $V_{z}$ at height $z$ in $\mathrm{m} / \mathrm{s} \mathrm{can} \mathrm{be}$ calculated mathematically as per Eq. 1.

$$
V_{z}=V_{b} k_{1} k_{2} k_{3} k_{4}
$$

Here, $k_{1}$ is risk factor or probability factor. It is decided based on design life of structures. $k_{2}$ is the velocity profile multiplier based on the terrain category. $k_{3}$ is topography factor, decided based on the ground slope of the site. $k_{4}$ is a factor based on the cyclonic importance of the structure.

The wind pressure in $\mathrm{N} / \mathrm{m}^{2}$ at any height $z$ above the mean ground level can be obtained from the following Eq. 2.

$$
p_{z}=0.6 V_{z}^{2}
$$

99 Finally design wind pressure $\left(p_{d}\right)$ in $\mathrm{N} / \mathrm{m}^{2}$ at any height $z$ above the mean ground level can be obtained from the following Eq. 3.

$$
p_{d}=K_{d} K_{a} K_{c} p_{z}, p_{d} \geq 0.7 p_{z}
$$

201 Design moment, shear and axial forces in beams and columns for wind load are calculated by applying the design wind pressure on the frame.

\subsubsection{Seismic loads}


When, any structure is subjected to seismic load dynamic equation of the structure can be represented as Eq. 4.

$$
[M] \ddot{x}(t)+[C] \dot{x}(t)+[K] x(t)=-[M] \ddot{u_{g}}(t)
$$

206 Where, $[M],[C]$ and $[K]$ are mass, damping and stiffness matrix of the structure. $\ddot{u_{g}}(t)$ is the

207

208

209

210

211

212

213

214

215

216

217

218

219

220

221

222

223

224

225

226

227

228

229

230

231 acceleration time history of the induced earthquake. $x(t)$ is the time history response of the structure due to the induced earthquake force. Equation 4 can be solved using numerical approaches for time history responses, such as displacement $x(t)$, velocity $\dot{x}(t)$ and acceleration $\ddot{x}(t)$. Eventually stress time history also can be obtained. But, there are some difficulties to do an actual seismic analysis for every structure to be designed. They are

i) It is not always possible to have the earthquake acceleration time history of the exact location of the structure.

ii) Analysis of the structure cannot be carried out solely considering the peak ground acceleration (PGA) of the earthquake, as the response of the structure depends on the frequency component of the earthquake and its own dynamic properties.

These difficulties can be overcome by using the response spectrum of the earthquake instead of using the acceleration time history as input. Response spectrum represents the maximum response of damped single degree of freedom (SDOF) system for a particular input earthquake motion at different natural period. Maximum response is more important to a designer than the entire time history. One can also obtain mean response spectrum for a particular location using more than one data of past earthquakes of the location. Also, use of different damping value will give different response spectrum for same earthquake response. Once acceleration response spectrum is known, one can easily obtain the maximum base shear simply by multiplying the spectral acceleration obtained from the response spectrum with the seismic mass of the structure. Every country develops their own design response spectrum based on the past earthquake happenings in the region. In general seismic design practice the structure should prevent non-structural damage for minor earthquake, prevent structural damage with minimum non-structural damage for moderate earthquake and avoid collapse to save lives in case of a major earthquake. Thus, no one use the spectral acceleration associated with PGA (maximum considered earthquake (MCE)) for seismic 
design of structure. Rather, the analysis is carried out for a much reduced value of spectral acceleration (design basis earthquake (DBE)).

The guidelines for analyzing a building frame for seismic loading is mentioned in IS 1893(Part-I)[45]. Instead of solving rigorous dynamic equations, Indian standard has provided simple linear static approach for simple regular structures utilizing the response spectrum. Entire country has been divided into four seismic zone (II, III, IV, V) based on the PGA. Seismic forces has two horizontal and one vertical components. For simple regular building frame vertical component is ignored. The design horizontal seismic coefficient $\left(A_{h}\right)$ can be calculated as Eq. 5 .

$$
A_{h}=\frac{\left(\frac{Z}{2}\right)\left(\frac{S_{a}}{g}\right)}{\left(\frac{R}{I}\right)}
$$

241 Here, $Z$ is seismic zone factor depend on the seismic zone of the location of the structures. In 242 the term $\left(\frac{Z}{2}\right),\left(\frac{1}{2}\right)$ factor used to reduce the MCE to DBE.I is the importance factor, decided 243 based on the occupancy and use of the structure. $R$ is the response reduction factor depends on 244 the ductility, redundancy and overstrength of the structure. A structure with good ductility 245 will have high value of $R$, i.e., that structure will be designed for low seismic force. $\left(\frac{s_{a}}{g}\right)$ is 246 normalize spectral acceleration coefficient, which can be calculated based on the natural 247 period of the structure and soil type from the design response spectrum presented in the 248 standard (Fig. 2).

249 The natural period of ordinary RC building can be calculated from Eq. 6.

$$
T_{a}=\frac{0.09 H_{b l}}{\sqrt{D_{b l}}}
$$

250 Now, the base shear can be computed for the building as a whole from the following 251 equation (Eq. 7).

$$
V_{B}=A_{h} W
$$


254 The base shear in Eq.7 is distributed at the center of mass of all the floor levels of the frame.

255 These forces are distributed to the individual lateral load resisting elements through structural 256

where, $W$ is the seismic weight of the building which is calculated by adding full dead load and 25 percent of the liveload. analysis considering floor diaphragm action.

\subsubsection{Load combinations}

All the above loads are considered for suitable load combinations according toIS 875 (Part V)[46] with appropriate load factors. The load combinations have been mentioned below

$$
\text { 1. 1.5(DL + LL) }
$$

$$
\text { 2. 1.5(DL } \pm \mathrm{WL})
$$

3. (0.9DL $\pm 1.5 \mathrm{WL})$

$$
\text { 4. } 1.5(\mathrm{DL} \pm \mathrm{SL})
$$

$$
\text { 5. (0.9DL } \pm 1.5 \mathrm{SL})
$$

6. 1.2(DL+LL $\pm \mathrm{WL})$

$$
\text { 7. 1.2(DL+LL } \pm \text { SL) }
$$

Among all these load combinations only most critical load combination has been used for designing each beam and column of the building frames.

\subsection{Structural design}

Beams and columns of all the frames were designed adopting Limit State Method as per the guidelines provided in the Indian Standard IS 456 [40] in the present study. The design procedure has been described briefly in the following sections.

\subsubsection{Beam design}

The design of beam is carried out based on limit state of collapse in flexure considering plane section normal to the axis remains plane after bending. Longitudinal reinforcements in 
beams are provided to carry bending moments, whereas stirrups are provided to carry shear forces. Design bending moment $\left(M_{u}\right)$ and shear forces $\left(V_{u}\right)$ for all beam sections are obtained 279 from the structural analysis. At first the beam is designed to carry design bending moment. 280 The limiting moment of resistance of balanced singly reinforced beam section due to flexure 281 can be calculated as per Eq. 8.

$$
M_{u, l i m}=0.36 \frac{x_{u \max }}{d_{e}}\left(1-0.42 \frac{x_{u \max }}{d_{e}}\right) b d_{e}{ }^{2} f_{c k}
$$

282 If $M_{u} \leq M_{u, \text { lim }}$, then the beam section is designed as singly reinforced section. The required 283 area of tensile reinforcement can be calculated from equation Eq. 9.

$$
M_{u}=0.87 f_{y} A_{s t} d_{e} \frac{x_{u \max }}{d_{e}}\left(1-\frac{f_{y} A_{s t}}{b d_{e} f_{c k}}\right), \quad A_{s t} \geq 0.85 b d_{e} / f_{y}
$$

284 If $M_{u}>M_{u, l i m}$, then the beam is designed as doubly reinforced section. Area of tensile 285 reinforcement $\left(A_{s t 1}\right)$ required for $M_{u, l i m}$ is calculated from equation Eq. 9. The area of 286 compression reinforcement for the excess moment i.e. $\left(M_{u}-M_{u, l i m}\right)$ is obtained from Eq. 28710.

$$
M_{u}-M_{u, l i m}=f_{s c} A_{s c}\left(d_{e}-d^{\prime}\right)
$$

where, $f_{s c}=$ design stress in compression reinforcement and it is obtained from Table I 289 (Appendix III) corresponding to a strain of $0.0035 \frac{\left(x_{u \max }-d^{\prime}\right)}{x_{u \max }}, \frac{x_{u \max }}{d_{e}}=0.53,0.48,0.46$ for $290 f_{y}=250,415,500$ respectively. The area of corresponding tensile reinforcement $\left(A_{s t 2}\right)$ for 291 the excess moment $\left(M_{u}-M_{u, l i m}\right)$ is calculated in Eq. 11.

$$
A_{s t 2}=f_{s c} A_{s c} / 0.87 f_{y}
$$

292 longitudinal reinforcement of beams are provided based on $A_{s t}, A_{s t 1}, A_{s t 2}$. Next, the provide 293 beam section is checked for design shear force. Nominal shear stress for beam section shall 294 be obtained from the following Eq. 12.

$$
\tau_{v}=V_{u} / b d_{e}
$$


295 The design shear strength $\tau_{c}$ of concrete is calculated from IS 456 [40] or Appendix IIIfor 296 grade of concrete and percentage of total tensile reinforcement provided.If $\tau_{v} \leq \tau_{c}$, minimum 297 shear reinforcement shall be provided as per in Eq. 13.

$$
s_{v}=\min \left(\frac{0.87 f_{y} A_{s v}}{0.4 b}, 3 d_{e}, 300 \mathrm{~mm}\right)
$$

298 If $\tau_{c}<\tau_{v}<\tau_{c \max }$, The shear reinforcement should be designed to carry a shear force $V_{u s}=$ $299 V_{u}-\tau_{c} b d_{e} \cdot \tau_{c m a x}$ can be obtained from IS 456 depending on the strength of the concrete. 300 (Table II, Appendix III) The spacing of the shear reinforcement shall be provided as obtained 301 from the following equation. Eq. 14.

$$
s_{v}=\min \left(\frac{0.87 f_{y} A_{s v} d_{e}}{V_{u s}}, \frac{0.87 f_{y} A_{s v}}{0.4 b}, 3 d_{e}, 300 \mathrm{~mm}\right)
$$

302 Once the longitudinal reinforcement and shear reinforcement had been designed, the beam 303 should be checked to be safe against the serviceability criteria of limit state method. Thus, 304 maximum deflection of the beam should be within the limit provided by the design standard. 305 The total deflection of beam is thus calculated as per Eq. 15.

$$
a_{t d}=a_{s}+a_{c s}+a_{c c}
$$

306 where, $a_{s}$ is calculated for the usual method for elastic deformation theory using short term 307 elasticity modulus $E_{c}$ and effective moment of inertia $I_{e f f}$ given in Eq. 16.

$$
\frac{I_{r}}{1.2-\frac{M_{r} Z}{M d_{e}}\left(1-\frac{x}{d_{e}}\right) \frac{b_{W}}{b_{b}}}, I_{r}<I_{e f f} I_{e f f}=<I_{g r}
$$

308 where, $M_{r}=f_{c r} I_{g r} / y_{t}, a_{c s}$ is the deflection due to shrinkage and it is calculated according to 309 the equation Eq. 17.

$$
a_{c s}=f_{3} \varphi_{c s} l^{2}
$$


310 where, $\varphi_{c S}=f_{4} \frac{\epsilon_{c S}}{D}$, where, $f_{3}, f_{4}$ are calculated from IS 456 [40] annex C-3.1. (Appendix

$311 \mathrm{III}) . \epsilon_{c s}=0.0003 . a_{c c}$ is the deflection due to creep for permanent loads and is defined in Eq. 31218

$$
a_{c c}=a_{i, c c}-a_{i}
$$

313 where, $a_{i, c c}$ is the initial plus creep deflection due to permanent loads obtained using an

314 elastic analysis with an effective modulus of elasticity $\left(E_{c e}=E_{c} /(1+\theta)\right)$.

\subsubsection{Column design}

The design of column is done based on the same assumption for limit state of collapse in

317 flexure i.e. plane section normal to the axis remains plane after bending. All compression 318 members should be designed for a minimum eccentricity of load in two principal direction. 319 Minimum eccentricity in design of columns can be obtained from Eq. 19.

$$
e_{\min }=\min \left(\frac{l_{c}}{500}+\frac{D_{c}}{30}, 20 \mathrm{~mm}\right)
$$

320 All the column sections are designed considering combined effects of axial load and biaxial bending moments. Thus, minimum eccentricity should be checked for both $\mathrm{x}$ and $\mathrm{y}$ direction bending separately. If the column is subjected to axial load $P_{u}$, biaxial moments $M_{u x}$ and $M_{u y}$, the column section thus designed should satisfy for interaction ratio given by Eq. 20 .

$$
\left(\frac{M_{u x}}{M_{u x 1}}\right)^{\alpha_{n}}+\left(\frac{M_{u y}}{M_{u y 1}}\right)^{\alpha_{n}} \leq 1.0
$$

$324 \alpha_{n}$ is the exponent component whose value depends on $P_{u} / P_{u z} \cdot \alpha_{n}=1$ for $P_{u} / P_{u z} \leq$ 325 0.2. $\alpha_{n}=2$ for $P_{u} / P_{u z} \geq 0.8$. Linear interpolation should be used for intermediate values. 326 $P_{u z}$ is calculated from Eq. 21 .

$$
P_{u z}=0.45 f_{c k} \mathrm{~A}_{\mathrm{c}}+0.75 f_{y} A_{s c c}
$$
combined with the axial load $P_{u}$ respectively for about $x$ and $y$ direction. Now, while 
considering any particular direction bending two different cases can emerge based on the position of the neutral axis as shown in Fig. 3.

331

Case 1: When the neutral axis lies within the column section (Fig. 3b), the axial load 332 carrying capacity and moment carrying capacity of the section can be calculated from Eq. 22 and Eq. 23 respectively.

$$
\begin{gathered}
P_{u 1}=0.36 k f_{c k} b_{c} D_{c}+\sum_{i=1}^{n} \frac{p_{i} b_{c} D_{c}}{100} *\left(f_{s i}-f_{c i}\right) \\
M_{u 1}=0.36 k f_{c k} b_{c} D_{c}^{2}(0.5-0.416 k)+\sum_{i=1}^{n} \frac{p_{i} b_{c} D_{c}}{100} *\left(f_{s i}-f_{c i}\right) y_{i}
\end{gathered}
$$

where $k=x_{u} / D$

Case 2: If neural axis lies outside the column section (Fig. 3c) the axial load carrying 336 capacity and moment carrying capacity of the section can be calculated from Eq. 24 and Eq. 25 respectively.

$$
\begin{gathered}
P_{u 1}=C_{1} f_{c k} b_{c} D_{c}+\sum_{i=1}^{n} \frac{p_{i} b_{c} D_{c}}{100} *\left(f_{s i}-f_{c i}\right) \\
M_{u 1}=C_{1} f_{c k} b_{c} D_{c}\left(0.5 D_{c}-C_{2} D_{c}\right)+\sum_{i=1}^{n} \frac{p_{i} b_{c} D_{c}}{100} *\left(f_{s i}-f_{c i}\right) y_{i}
\end{gathered}
$$

338 where, $f_{c i}$ is stress in concrete at the level of $\mathrm{i}$-th row of reinforcement and can be calculated 339 from Fig. 3d. $f_{s i}$ is stress in the i-th row of reinforcement can be obtained from Table III 340 (Appendix III). $C_{1}$ is stress co-efficient and $C_{2} D$ is the distance of the centroid the concrete 341 stress block (Fig. 3d) measured from the highly compressed edge. $C_{1}$ and $C_{2}$ can be obtained 342 from Eq. 26 and Eq. 27 respectively.

$$
C_{1}=\frac{\mathrm{A}_{\mathrm{str}}}{f_{c k} D_{c}}
$$




$$
C_{2}=M_{c} / \mathrm{A}_{\mathrm{str}}
$$

$343 A_{s t r}$ is the area of the stress block (Fig.3d), and can be calculated from the Eq. 28.

$$
A_{s t r}=0.446 f_{c k} D_{c} *\left(1-\left(\frac{4}{21}\right)\left(\frac{4}{(7 k-3)}\right)^{2}\right)
$$

$344 M_{C}$ is the moment of the concrete stress block (Fig. 3d) about highly compressed edge is 345 obtained as per Eq. 29.

$$
M_{c}=0.446 f_{c k} D_{c} *\left(0.5 * D_{c}\right)-(8 / 49) * g * D_{c}^{2}
$$

346 Where $g$ is geometric properties of the parabola (Fig. 3d) obtained from Eq. 30.

$$
g=\left(0.446 f_{c k} *\left(\frac{4}{7 k-3}\right)^{2}\right)
$$

347 Diameter of tie bar of a column section $\left(\varphi_{\text {tie }}\right)$ should be decided according to Eq. 31 .

$$
\varphi_{\text {tie }}=\max \left(\frac{\varphi_{m}}{6}, 6 \mathrm{~mm}\right)
$$

348 Spacing of tie bar $\left(S_{\text {tie }}\right)$ can be calculated according to Eq. 32.

$$
S_{t i e}=\min \left(16 \varphi_{t i e}, 300 \mathrm{~mm}\right)
$$

349

350

\subsection{Structural Design Optimization}

\subsubsection{Unified Particle Swarm Optimization (UPSO)}

UPSO is a swarm based optimization proposed by Parsopoulos and Vrahitis [47] as a upgraded version of Particle swarm optimization (PSO) [48, 49] based on the individual and social behavior of flock of birds, school of fish etc. in their process of searching foods or avoiding predators. 
356

357

358

359

360

361

362

363

364

The updated velocity can be obtained from Eq. 34 .

$$
\begin{aligned}
& H(t+1)=\mu G(t+1)+(1-\mu) L(t+1), H(t+1) \in\left[-H_{\text {max }}, H_{\text {max }}\right] \\
& G(t+1)=\chi\left[H(t)+c_{1} \operatorname{rand}(0,1)(a(t)-S(t))+c_{2} \operatorname{rand}(0,1)(u(t)-S(t))\right] \\
& L(t+1)=\chi\left[H(t)+c_{1} \operatorname{rand}(0,1)(a(t)-S(t))+c_{2} \operatorname{rand}(0,1)(n(t)-S(t))\right]
\end{aligned}
$$

365

$\mu$ is unification factor increasing from 0 to 1 exponentially according to Eq. 37

$$
\mu(t)=\exp \left(\frac{t * \log 2}{\text { MaxIt }}\right)-1
$$

366

367

368

Also, $S_{\max }$ and $S_{\text {min }}$ are upper and lower limit for position respectively. $V_{\text {max }}$ is upper limit for velocity $=\left(S_{\max }-S_{\min }\right) / 2, \chi=0.729$, and $c_{1}=c_{2}=2.05[50]$.

\subsubsection{Beam and column design optimization}

369

Beam and column design optimizations algorithm are developed by making suitable changes 370 in the above mentioned UPSO algorithm. In the present study beams and columns has been optimized separately. The entire algorithm is divided into three steps accordingly.

372

(A) UPSO based beam design optimization

373 
1. The input variables are considered as width $(b)$, overall depth $(D)$, diameter of main bar at top $\left(\varphi_{t}\right)$ and bottom $\left(\varphi_{b}\right)$,no of compression bar $\operatorname{support}\left(n_{c s}\right)$ and mid span $\left(n_{c m}\right)$, no of tension bar at support $\left(n_{t s}\right)$ and mid span $\left(n_{t m}\right)$.

2. Only longitudinal reinforcement are optimized along with the cross sectional area. Shear reinforcement are designed based on the optimized cross section and longitudinal reinforcement amount.

3. The output variables are width, overall depth, diameter of bar at top and bottom of section, number of bars at top and bottom for mid-span and support of section, spacing of shear reinforcement at support and mid-spanof section.

4. The following constraints are considered
a. $1.5 b \leq D \leq 2 b$

b. $b$ and $D$ are assumed in the multiple of 10 to take into account the practicality aspects of construction.

c. Clear spacing of the bars should exceed the maximum aggregate size.

d. Moment and shear capacity of section should exceed the design moment and shear of that section.

e. Total deflection (Eq. 14) should be less than $\frac{1}{250}$.

Detailed algorithm of UPSO based RC beam design optimization have been presented in Algorithm 1 of Appendix II.

(B) UPSO based column design optimization

In the second step all column are optimized separately. In case of column design optimization

1. The input design variables considered are as follows: width $\left(b_{c}\right), \operatorname{depth}\left(D_{c}\right), k_{x}, k_{y}$, diameter of main bars $\left(\varphi_{m}\right)$, number of main bars of columns in $x$ and $y$ directions (n). 

417 [51]).

418 Area of formwork $\left(A_{f}\right)$ for beam and columns can be calculated from Fig. 5 as per Eq. 39 and 419 Eq. 40 respectively

$$
\begin{gathered}
\left(A_{f}\right)_{\text {beam }}=(b+2 D) * \text { length of beam } \\
\left(A_{f}\right)_{\text {column }}=\left(2 b_{c}+2 D_{c}\right) * \text { length of column }
\end{gathered}
$$




\section{Numerical results and discussion}

422

423

424

425

426

427

428

429

430

431

432

433

434

435

436

437

438

439

440

441

442

443

444

445

446

447

448

449

450

\subsection{Problem definition}

One G+8 L shaped building frame (Fig. 6a) and one G+10 U shaped building frame (Fig. 6b) are considered to demonstrate the efficacy of proposed algorithm. The structures were analyzed in STAADPro V8i [52] considering seismic loads, wind loads and gravity loads to determine the most critical load case for each member. Now, an UPSO based algorithm has been developed to obtain cost optimum design for beams and columns utilizing the design loads obtained from STAAD Pro [52] for critical load cases without disrupting the safety criteria. The designs ofeach beam and each columnare optimized separately to consider the contribution of all the design parameters responsible for beams and columns. The optimized cost of all beams and columns are summed up to get the total optimized cost for each frame. Efficient cost optimization algorithm of RC building frame depends on appropriate choice of design parameters and internal parameters for optimization algorithm.

\subsection{Design parameters}

Important design parameter considered in the present study has been mentioned below:

i) Location of the structure : Kolkata, India (assumed)

ii) Thickness of outer wall and inner wall $=250 \mathrm{~mm}$ and $125 \mathrm{~mm}$ respectively (outer walls and inner walls are assumed to be on outer and inner beam respectively).

iii) Unit weight of brick wall $=20 \mathrm{KN} / \mathrm{m}^{3}$ Unit weight of reinforced concrete $=25 \mathrm{KN} / \mathrm{m}^{3}$

iv) Floor finish load on roof $=1 \mathrm{KN} / \mathrm{m}^{2}$

v) Live on all roof $=1.5 \mathrm{KN} / \mathrm{m}^{2}$

Live load on all other floor $=3 \mathrm{KN} / \mathrm{m}^{2}$

vi) For wind load (IS 875(Part III) 2015) [44] (Appendix III) $V_{b}=50 \mathrm{~m} / \mathrm{s}, k_{1}=1$ (50 years life span) (Table IV, Appendix III), $k_{2}$ is function of height (Table $\mathrm{V}$ of Appendix III) for terrain category 2, $k_{3}=1$ (for ground slope $<3^{\circ}$ ), $k_{4}=1$ (ordinary $\mathrm{RC}$ frame).

$K_{d}=1, K_{a}=1, K_{c}=0.9$. The velocity profile of wind load analysis used in the analysis has been presented in Fig. 7.

vii) For seismic load (IS 1893(Part I)[45] 
$Z=0.16$ (Zone III), $I=1$ (Ordinary building), $R=3$ (ordinary moment resisting frame), soil type: medium, $\frac{s_{a}}{g}$ can be calculated as per Fig. 2 .

Seismic weight is calculated considering full dead load, no live load on roof and half live load on all other floors

viii) Yield strength of reinforcement bar $=415 \mathrm{MPa}$ and Characteristic strength of concrete $=25 \mathrm{MPa}$ (assumed)

ix) Beams and columns are designed considering load reversal due to seismic and wind load cases. Reinforcement is placed only along the outer periphery of the sections. Equal number of reinforcement is placed on all the four sides of the columns. The space between two consecutive bars should be greater than maximum aggregate size for convenience of the construction. Curtailment of extra tensile bars in beam has been considered in present study (Fig. 8). Development length of reinforcement of beam and columns at the end supports has not been considered. In case of beam, different shear reinforcement spacing has been used for support and mid span as required as all the beams are continuous with fixed supports. Shear reinforcement for support has been designed for maximum shear force of beam, while shear reinforcement at the mid span designed to carry minimum shear.

x) Minimum and maximum diameter of main reinforcing bars for beams and columns are $12 \mathrm{~mm}$ and $32 \mathrm{~mm}$. The diameter of tie bar for shear in beams is 2 legged $8 \mathrm{~mm}$ and for columns are $8 \mathrm{~mm}$.

\subsection{Optimization parameters}

1. Beams are optimized starting from bottom floor to top floor. The search space of the beam design optimization has been restricted in such a way that the maximum value of optimization design variables for a particular floor shall be equal to the optimized design values obtained for the beams in the subsequent bottom floor (except for ground floor). The minimum range of the design variables of all beams have been kept same for all floors.

2. Columns are optimized starting from top floor to bottom floor. The search space of the column design optimization has been restricted in such a way that the minimum value of optimization design variables for a particular floor shall be equal to the optimized design values obtained for the columns in the subsequent top floor (except 
for topmost floor). The maximum range of the design variables of all beams have been kept same for all floors.

3. Individual beam and column design optimization are performed separately for 10 numbers of experiments considering maximum iteration and swarm size 50 and 10 respectively. The experiment which exhibit minimum cost has been considered as the optimized design for the respective beam and column.

4. In case of continuous beams, all spans have been designed considering the maximum design moments and shear for the beam.

\subsection{Numerical Results}

\subsubsection{L-shaped building frame}

In this section developed UPSO based algorithm has been used to optimize the RC design of the G+8 L-shaped building frame to have minimum cost. Search space of design variables should be decided appropriately depending on the experience of the designer, as inappropriate choice of search space can lead to large computational effort.Search space of design variables considered in the study in case of beams are: $b \in[200,400], D \in$ $[300,600], \quad \varphi_{t} \in[12,20], \varphi_{b} \in[12,20], \quad n_{c s} \in[2,5], n_{c m} \in[2,5], n_{t s} \in[2,5], n_{t m} \in[2,5]$. Search space of design variables considered in the study in case of columns are: $b_{c} \in$ $[250,500], D_{c} \in[250,500], \quad k_{x} \in[0.5,1.2], k_{y} \in[0.5,1.2], \quad \varphi_{m} \in[12,25], n \in$ $[2,4]$.Convergence curve for total cost for M20, M25, M30, and M35 grades of concrete along with Fe 415 steel have been plotted in Fig. 9(a). Total cost of the building frame is found to be varying within the range [3840101, 4014875] for Fe 415 steel and [3564230, 3942723] for Fe 500 steel for different grades of concrete. It can be observed that variation among different grades of concrete is $4.5 \%$ and $10.7 \%$ for Fe 415 and Fe 500 steel. Next, Fig. 9(b) has been plotted showing the convergence curves of the total cost of concrete, total cost formwork and total cost of steel through all the iterations for M20 grade of concrete and Fe415 grade of steel. This will give designers a good insight regarding the inter-relationship among these three parameters. Also, a bar diagram has been presented showing the comparisons of total cost of the frame for different grades of steel (Fe415, Fe500) and concrete (M20, M25, M30, M35) in Fig. 9(c). It can be seen that for all concrete grades, Fe 500 steel yields lower cost than Fe415 steel.Optimized design output for beams and columns obtained from the algorithm has been reported respectively in Table 2 and Table 3 for M20concrete and Fe 415 steel. Beam design details of only three floors have been presented 
515 for brevity (Table 2), whereas typical column design details for all the floors have been

516 presented (Table 3). In case of columns6 mm diameter of links are considered throughout and

517 the spacing is $190 \mathrm{~mm} \mathrm{c} / \mathrm{c}, 255 \mathrm{~mm} \mathrm{c} / \mathrm{c}$ and $300 \mathrm{~mm} \mathrm{c} / \mathrm{c}$ for $12 \mathrm{~mm}, 16 \mathrm{~mm}$, and $20 \mathrm{~mm}$

518 diameter main bars respectively.

519 Thus, the present algorithm has been found to be very flexible and effective to provide cost 520 optimized design for multistoried L shaped building, considering all the codalprovisions (IS 521456 [40]) and the practical considerations.

\section{3.4.2. U-shaped building frame}

523 In this section developed UPSO based algorithm has been used to optimize the RC design of 524 the G+10 U-shaped building frame to have minimum cost. Search space of design variables 525 should be decided appropriately depending on the experience of the designer, as inappropriate choice of search space can lead to large computational effort. Search space of

527

528

529

530

531

532

533

534

535

536

537

538

539

540

541

542

543

544

545

546 design variables considered in the study in case of beams are: $b \in[200,250], D \in$ $[500,300], \varphi_{t} \in[12,16], \varphi_{b} \in[12,16], n_{c s} \in[2,5], n_{c m} \in[2,5], n_{t s} \in[2,5], n_{t m} \in[2,5]$. Search space of design variables considered in the study in case of columns are: $b_{c} \in$ $[250,400], \quad D_{c} \in[250,400], \quad k_{x} \in[0.5,1.2], k_{y} \in[0.5,1.2], \quad \varphi_{m} \in[12,20], n \in$ $[2,3]$.Convergence curve for total cost for M20, M25, M30, and M35 grades of concrete along with Fe 415 steel have been plotted in Fig. 10(a). Total cost of the building frame is found to be varying within the range [2813601, 2898791] for Fe 415 steel and [2805123, 2813406] for Fe 500 steelfor different grades of concrete Hence, the maximum variation in total cost among different grades of concrete is found to be $3.03 \%$ and $0.30 \%$ for Fe 415 and Fe 500 steel respectively. Fig. 10(b) representsthe convergence curves of the total cost of concrete, total cost formwork and total cost of steel through all the iterations for M25 grade of concrete and Fe415 grade of steel.A bar diagram showing the total cost of frame was outlined in Fig. 10(c) for various grades of concrete (M20, M25, M30, M35) and steel (Fe415, Fe500). There is not much difference in the cost output for Fe 415 and Fe 500 as observed in the previous problem. It can be seen that for all concrete grades, Fe 500 steel yields lower cost than Fe415 steel. While beam design details of three different floors have been presented in Table 4, column design details has been presented in Table 5 for typical columns in all the floors. M25 concrete and Fe 415 steel are considered for design outputs of both the tables. The diameter and spacing of links in columns are similar to the results reported for L-shaped building frame.The present algorithm is adequately apt, suitably 
adaptable and effectively potent to provide cost optimized design of reinforced concrete buildings U- shaped building frame considering all the codal provisions(IS 456 [40])and practical considerations.

As optimization algorithms are based on random processes, possibility of coming up with a different solution is quite common when a large number of experiments are involved. However, the probability of the optimized objective function value to lie within an acceptable range decides the robustness of the optimization algorithm. For that, a large number of experiments are required and each and every solution should be checked whether it is in the acceptable range of the optimum solution. It is a very time consuming and rigorous to conduct a huge number of experiments (i.e. 5000 or 10,000) on the developed algorithm and check every solution manually. In that case, the Monte Carlo simulation (Metropolis and Ulam[53], Metropolis [54]) is used to assess the variations of the solutions of the developed algorithm for large of number of experiments. However, the variations in results should be within an acceptable range for an engineer to accept the results. Monte Carlo simulation is a mathematical numerical method that uses random draws to perform calculations and complex problems. The method was first introduced by Stanislaw Ulam (Eckhardt [55]) and is based on the game of dice, roulette etc. Monte Carlo simulation can be used create large number of solutions of the problem in hand numerically from a small available number of solutions based on a normal distribution curve or bell curve. Then the normal distribution curve can be used to obtain the forecast of the favorable solution and its probability. The probability of the occurrence of the favourable solution among a large number of experiments can be estimated in the normal distribution curve. This decides the robustness of the developed algorithm.

570

In the present study aMonte Carlo simulation for 5000 probable solutions (total cost of 571 frames) of the developed algorithm was performed using MS excel.The expression for probable solution of each simulation was worked out using the following expression in Eq. 573 41.

$$
\text { tot_cost } t_{i+1}=\text { tot }_{-} \operatorname{cost}_{i} \times e^{D_{r}+R}, i=1,2, \ldots, 5000
$$




$$
\begin{gathered}
D_{r}=\mu_{E}-\sigma^{2} / 2 \\
R=\sigma \times n o r m \operatorname{sinv}(\operatorname{rand}(0,1))
\end{gathered}
$$

575 Where, normsinv is an excel function which returns probability corresponding to the 576 standard normal distribution with a mean of zero and a standard deviation of one. $\mu_{E}$ and $\sigma$ 577 are respectively mean and standard deviation of the 10 number of available total cost values. $578 \mu_{E}$ is considered as tot_cost ${ }_{i}$ for calculating the values for first simulation.

579 Summary of results of 10 numbers of experiments obtained employing the optimization 580 algorithm along with the key solution of Monte Carlo simulation is presented in Table 6 and 581 Table 7 for L-shaped building frame and U-shaped building frame respectively. Total cost of 582 L-shaped and U-shaped building frame are found to be lying in the ranges of [3792373.03, 583 3923637.97] and [2833889.28, 2887321.15] respectively after 5000 simulations. These 584 ranges are divided into 20 equal divisions. The probability of total cost falling within each 585 interval was estimated considering 5000 forecasted solutions. These probability values 586 obtained for 20 intervals are plotted in Fig. 11 and Fig. 12 for L-shaped and U-shaped frames respectively. Both the plots clearly depict the nature of a normal distribution curve. The most likely solution is at the middle of the curves, meaning there is an equal chance that the actual solutionwill be higher or lower than that value. The key percentile shows the likely values of the total cost of frames.For example, the key percentile value against the $25 \%$ shows that there is $25 \%$ chance that the developed algorithm will provide this total cost. Similarly, key percentiles for $50 \%$ and $75 \%$ chance have also been evaluated. Key percentile values are presented in Table 6 and Table 7 for L-shaped and U-shaped building frame respectively.Also, the total cost corresponding to $99 \%$ for both the frames also proves that there is negligiblescope for design failure by the developed algorithm. Loss percentile is calculated keeping the maximum total cost to be Rs. 39, 00,000 and Rs. 28, 80,000 for Lshaped and U-shaped frame respectively. The loss percentile shows that there is only $2 \%$ chance of the total cost to exceed Rs. 39, 00,000 (Table. 6) for L-shaped frame and 0.6\% chance to exceed Rs. 28, 80,000 (Table 7) for U-shaped frame, which are very close to first simulation values. The loss percentages are found to be very negligible. Therefore, the optimum design of the frames using the developed algorithm is not only found safe in every experiments but it also provide an optimum overall cost almost every time. 
In the present algorithm beams and columns are optimized separately and added later to

605

606

607

608

609

610

611

612

613

614

615

616

617

618

619

620

621

622

623

624

625

626

627

628

629

630

631

632

633

634 obtain the optimized design for the entire frame. Therefore, the stiffness redistribution among beams and columns due to varying sizes of them in each iteration of the optimization have not been taken into account. Thus, from mathematical point of view slight error has been imparted into the analysis. In the present algorithm a few measures have been taken to ensure the safety of the structures. The analysis and preliminary design of the buildings are performed in STAAD Pro, in such way that sizes of all beams and columns has been chosen in a conservative manner. It was then made sure that design was safe as per design standard. Next, design forces (shear force, moment and axial forces) have been taken from the conservative STAAD Pro model and fed into the developed optimization algorithm in MATLAB. In that way the sizes of beams and columns only reduced during optimization procedure as can be seen from Table 2-5. The design force is kept same as the preliminary analysis of STAAD Pro. In that way, it has been made sure that design was always carried out for design forces higher than the actual design forces obtained during the course of the optimization program. After optimization is done, optimized member sizes are incorporated in STAADPro model to compare the design forces of optimized structures with actual STAADPro model. Table 8-9 have been presented showing the comparison between the design forces of the structures before and after optimization for a typical fourth floor of one building (L-shaped). Actual design forces and moments of optimized structure are observed to be significantly lower than the design forces and moments of the structure before optimization. So, the optimized design has been indeed carried out for higher design forces and moments than the actual. Therefore, the aforementioned error has not influence the safety of the buildings significantly enough to violate the safety criteria provided by the design standard. So, from practical civil engineering point of view the design results obtained from present algorithm is feasible and safe enough to be used for cost-optimum design of RC building frame.

\section{Conclusion}

In the present study, an UPSO based optimization algorithm has been developed in MATLAB [56]environment to find cost optimum design of reinforcement concrete building frame considering the codal specifications of safety and serviceability of IS 456 [33] along with the consideration for the construction requirements in practical field. 
635 Two building frames namely G+8 L-shaped frame and G+10 U-shaped frame have been 636 adopted to demonstrate the efficacy of the developed algorithm. Popular design and analysis 637 software STAADPro. V8i [52] has been used to obtain the design forces (bending moments, 638 shear forces and axial forces) in critical sections of all the beams and columns considering the 639 effects of gravity loads, wind loads and seismic loads as per the specifications of the 640 respective Indian Standards. Next, each beam and column are optimized separately 641 employing UPSO based algorithm. Thus, total optimized cost of the frames hasbeen obtained 642 by adding up all the optimized costs of these beams and columns. Numerical results have 643 revealed that the present algorithm is capable of providing cost optimized design of RC 644 frames of any shape and height with profound accuracy.Further, Monte Carlo

645 simulationperformed assures the consistency and robustness of the developed algorithm with 646 almost hundred percent design success. This further confirms that the algorithm can be 647 effectively used for optimal design of any type of reinforced concrete buildings having 648 different design constraints. Only the design variables and constraints need to be modified to 649 adapt to the particular building problem. Overall, the present UPSO based algorithm has been 650 found to be very effective in finding cost optimum design of RC frame having any planner 651 irregularity and any number of floors. The positive findings of the research will encourage the 652 future researchers to improve the present algorithm to incorporate more minute reinforcement 653 details such as development length, ductile detailing etc.Also, finite element method can be 654 incorporated within the algorithm to obtain the design forces directly instead of relying on 655 commercial design software. In that way accuracy of the results can be improved further.

656

\section{Data availability statement}

658 All the required data presented in the manuscript itself. Any further dataimportant to the 659 readers can be made available as per their request.

\section{Acknowledgement}

661 The author wish to acknowledge anonymous reviewers for their valuable suggestions and 662 comments. The authors are grateful to department of Civil Engineering, IIT Kharagpur to 663 provide the necessary infrastructure to carry out the research work.

\section{Conflict of interest}


665 On behalf of all authors, the corresponding author states that there is no conflict of interest.

\section{Replication of results}

667 The authors hereby statethat they are willing to share all the codes and numerical data needed 668 to reproduce the figures.

669 
670

671

672

673

674

675

676

677

678

679

680

681

682

683

684

685

686

687

688

689

690

691

692

693

694

695

696

[1] Milajić, A., Pejicic, G., and Beljakovic, D. (2013). "Optimal Structural Design of Reinforced Concrete Structures - Review of Existing Solutions." Archives for Technical Sciences, 9(1), 53-60.

[2] Hasencebi, O., Teke, T., and Pekcan, O. (2013). "A bat-inspired algorithm for structural optimization." Computers and Structures, 128, 77-90.

[3] Wang, L., Zhang, H. and Zhu, M. (2020). "A new Evolutionary StructuralOptimization method and application for aided design to reinforced concretecomponents." Struct Multidisc Optim. https://doi.org/10.1007/s00158-02002626-z.

[4] Lu, H., Gilbert, M. and Tyas, A. (2019). "Layout optimization of building frames subject to gravity and lateral load cases". Struct Multidisc Optim 60, 1561-1570.

[5] Lee, J. (2019). "Multi-objective optimization case study with active and passive design in building engineering." Struct Multidisc Optim 59, 507-519.

[6] Zegard, T., Hartz, C., Mazurek, A. (2020). “Advancing building engineering through structural and topology optimization." Struct Multidisc Optim. https://doi.org/10.1007/s00158-020-02506-6.

[7] Prakash, A., Agarwala, S. K., and Singh, K. K. (1988). "Optimum design of reinforced concrete sections." Computers and Structures, 30(4), 1009-1011.

[8] Chakrabarty, B. K. (1992). "Models for optimal design of reinforced concrete beams." Computers and Structures, 42(3), 447-451.

[9] Coello, C. C., Hernández, F. S., and Farrera, F. A. (1997). "Optimal design of reinforced concrete beams using genetic algorithms." Expert Systems with Applications, 12(1), 101-108.

[10] Rajeev, S., and Krishnamoorthy, C. S. (1998). "Genetic algorithm-based methodology for design optimization of reinforced concrete frames." ComputerAided Civil and Infrastructure Engineering, 13(1), 63-74. 
[11] Dole, M. R., Ronghe, G. N., and Gupta, L. M. (2000). "Optimum design of reinforced concrete beams using polynomial optimization technique." Advances in Structural Engineering, 3(1), 67-79.

[12] De Medeiros, G. F., and Kripka, M. (2013). "Structural optimization and proposition of pre-sizing parameters for beams in reinforced concrete buildings." Computers and Concrete, 11(3), 253-270.

[13] Nigdeli, S. M., and Bekdaş, G. (2017). “Optimum design of RC continuous beams considering unfavourable live-load distributions." KSCE Journal of Civil Engineering, 21(4), 1410-1416.

[14] Uz, M. E., Sharafi, P., Askarian, M., Fu, W., and Zhang, C. (2018). “Automated layout design of multi-span reinforced concrete beams using charged system search algorithm.” Engineering Computations, 35(3), 1402-1413.

[15] Ferreira, C. C., Barros, M. H. F. M., and Barros, A. F. M. (2003). “Optimal design of reinforced concrete T-sections in bending." Engineering Structures, 25(7), 951964.

[16] Preethi, G., and Arulraj, P. G. (2016). "Optimal Design of Axially Loaded RC Columns." Bonfring International Journal of Industrial Engineering and Management Science, 6(3), 78-81.

[17] Bekdaş, G., and Niğdeli, S. M. (2016). "Optimum design of reinforced concrete columns employing teaching-learning based optimization." Challenge Journal of Structural Mechanics, 2(4), 216-219.

[18] Aldwaik, M. and Adeli, H. (2016). "Cost optimization of reinforced concrete flat slabsof arbitrary configuration in irregular highrise building structures." Struct MultidiscOptim54, 151-164.

[19] Aldwaik, M. and Adeli, H. (2014). "Advances in optimization of highrisebuildingstructures." Struct Multidisc Optim50, 899-919.

[20] Chaudhuri, P. and Maity, D. (2020).“Cost optimization of rectangular RC footing using GA and UPSO.” Soft Computing, 24 (January), 709-721 
[21] Kaveh, A., and Behnam, A. F. (2013). "Design optimization of reinforced concrete 3D structures considering frequency constraints via a charged system search." ScientiaIranica, Elsevier B.V., 20(3), 387-396.

[22] Bekdaş, G., and Nigdel, S. M. (2014). "Optimization of RC frame structures subjected to static loading." 11th World Congress on Computational Mechanics, WCCM 2014, 5th European Conference on Computational Mechanics, ECCM 2014 and 6th European Conference on Computational Fluid Dynamics, ECFD 2014, (Wccm Xi), 3869-3875.

[23] Aga, A. A. A., and Adam, F. M. (2015). "Design Optimization of Reinforced Concrete Frames." Open Journal of Civil Engineering, 05(01), 74-83.

[24] Gharehbaghi, S., and Khatibinia, M. (2015). "Optimal seismic design of reinforced concrete structures under time- history earthquake loads using an intelligent hybrid algorithm." Earthquake Engineering and Engineering Vibration, 14(1), 97-109.

[25] Esfandiary, M. J., Sheikholarefin, S., and Bondarabadi, H. A. R. (2016). "A combination of particle swarm optimization and multi-criterion decision-making for optimum design of reinforced concrete frames." International Journal of Optimization in Civil Engineering, 6(2), 245-268.

[26] Kulkarni, A., and Bhusare, V. (2017). "Structural optimization of reinforced concrete structures Structural Optimization of Reinforced Concrete Structures." International Journal of Engineering Research \& Technology (IJERT), 5(March), $123-127$.

[27] Bekas, G. K., and Stavroulakis, G. E. (2017). "Machine Learning and Optimality in Multi Storey Reinforced Concrete Frames.” Infrastructures, 2(2), 6.

[28] Tapao, A., and Cheerarot, R. (2017). "Optimal parameters and performance of artificial bee colony algorithm for minimum cost design of reinforced concrete frames.” Engineering Structures, Elsevier Ltd, 151, 802-820.

[29] Esfandiari, M. J., Urgessa, G. S., Sheikholarefin, S., and Manshadi, S. H. D. (2018). "Optimum design of 3D reinforced concrete frames using DMPSO algorithm." Advances in Engineering Software, 115(September 2017), 149-160. 
[30] RazmaraShooli, A., Vosoughi, A.R. and Banan, M.R. (2019). “A mixed GA-PSObased approach for performance-based design optimization of $2 \mathrm{D}$ reinforced concrete special moment-resisting frames." Applied Soft Computing Journal, 85(105843).

[31] Milajić, A., Beljakovic, D., and Culic, N. (2014). "Optimal Structural Design Based on Applicability in Practice." In conference proceedings of People, People, Buildings and Environment, Kroměříž, Czech Republic, 306-315.

[32] Milajić, A., Prokic, A., Beljakovic, D., and Pejicic, G. (2015). "Quantitative method for evaluating applicability of designed reinforcement pattern." Kvantitativnimetodzaocjenuprimjenljivostiprojektiraneshemearmiranja, 22(1), $119-124$.

[33] Nanda, B., Maity, D., Maiti, D.K. (2014). "Modal parameter based inverse approach for structural joint damage assessment using unified particle swarm optimization."Applied Mathematics and Computation, 242(1), 407-422.

[34] Nanda, B., Maity, D., Maiti, D.K. (2014). "Damage assessment from curvature mode shape using unified particle swarm optimization." Structural Engineering and Mechanics Volume, 52(2), 307-322.

[35] Mohan, S. C., Maiti, D. K and Maity, D. (2013) "Structural damage assessment using FRF employing particle swarm optimization" Applied Mathematics and Computation, 219 (20), 10387-10400.

[36] Barman S.K., Maiti D.K., Maity D. (2020) Damage Detection of Truss Employing Swarm-Based Optimization Techniques: A Comparison. In: Venkata Rao R., Taler J. (eds) Advanced Engineering Optimization Through Intelligent Techniques. Advances in Intelligent Systems and Computing, 949.21-37 Springer, Singapore.

[37] Barman, S. K., Jebieshia, T. R., Tiwari, P, Maiti, D.K. and Maity, D. (2019) "TwoStage Inverse Method to Detect Delamination in Composite Beam Using Vibration Responses” AIAA Journal. 57 (3). 1312-1322.

[38] Mishra, M., Barman, S. K, Maity, D and Maiti, D. K. (2020). "Performance Studies of 10 Metaheuristic Techniques in Determination of Damages for Large- 
Scale Spatial Trusses from Changes in Vibration Responses." Journal of Computing in Civil Engineering, 34 (2), 04019052.

785

786

787

788

789

790

791

792

793

794

795

796

797

798

799

800

801

802

803

804

805

806

807

808

809

810

[39] Parsopoulos, K.E., Kariotou, F., Dassios, G. and Vrahatis, M.N. (2009). 'Tackling magnetoencephalography with particle swarm optimization'. International Journal of Bio-Inspired Computation, 1(1-2), 32-49

[40] IS 456 (2000). Plain and Reinforced Concrete - Code of Practice, Bureau of Indian Standards, New Delhi, India

[41] IS 875 (Part I) (1987). Code of practice for design loads (other than earthquake)for buildings and structures: part 1 dead loads - unit weights of building material and stored materials, Bureau of Indian Standards, New Delhi, India

[42] IS 875 (Part II) (1987). Code of practice for design loads (other than earthquake) for buildings and structures: part 2 imposed loads, Bureau of Indian Standards, New Delhi, India

[43] SP 64 (Part III) (2001). Explanatory handbook on Indian standard code of practice for design loads (other than earthquake) for buildings and structures, Bureau of Indian Standards, New Delhi, India

[44] IS 875 (Part III) (2015). Design loads (other than earthquake) for buildings and structures - code of practice - part 3 wind loads, Bureau of Indian Standards, New Delhi, India

[45] IS 1893 (Part I) (2016). Criteria for earthquake resistant design of structures - part 1: general provisions and buildings, Bureau of Indian Standards, New Delhi, India

[46] IS 875 (Part V) (2015). Code of practice for design loads (other than earthquake)for buildings and structures: part 5special loads and load combinations, Bureau of Indian Standards, New Delhi, India

[47] Parsopoulos, K. E., and Vrahatis, M. N. (2005). "Unified Particle Swarm Optimization for Solving Constrained Engineering Optimization Problems." Advances in natural computation, Springer, Springer Berlin Heidelberg, Berlin, Heidelberg, 582-591. 
811

812

813

814

815

816

817

818

819

820

821

822

823

824

825

826

827

[48] Kennedy, J. and Eberhert, R. (1995). "Particle swarm optimization.” International Conference on Neural Networks, IEEE, Australia.

[49] Perez, R. E., and Behdinan, K. (2007). "Particle swarm approach for structural design optimization." Computers and Structures, 85(19), 1579-1588.

[50] Parsopoulos, K. E., and Vrahatis, M. N. (2010).Particle Swarm Optimization and Intelligence, Vol. 270, 2010. doi:10.4018/978-1-61520-666-7.

[51] WB PWD schedule.(2017) Schedule of rates, volume I: building works. Public Works Department (PWD), Government of West Bengal (WB), India

[52] STAAD Pro V8i (2017). Select series 6, Bentley Systems, Inc. PA, USA.

[53] Metropolis, N., andUlam, S. (1949). “The Monte Carlo Method.”Journal of the American Statistical Association, 44(247), 335-341. doi:10.2307/2280232

[54] Metropolis, N. (1987). The beginning of the Monte Carlo method. Los Alamos Science15: $125-130$

[55] Eckhardt, R. (1987). "Stan Ulam, John Von Neumann, and the Monte Carlo method." Los Alamos Science, 15, 131--136.

[56] MATLAB (2015), TheMathworks Inc. USA. 
828

829

830

831

832

833

834

835

836

837

838

839

840

841

842

843

844

845

846

847

848

\section{APPENDIX I. Notation}

The following symbols have been used in this paper:

$A_{h}=$ Horizontal acceleration coefficient

$W=$ Seismic weight of building

$Z=$ Seismic zone factor

$\frac{S_{a}}{g}=$ Design acceleration coefficient

$T_{a}=$ Natural period of building

$H_{b l}=$ Height of the building from plinth level

$D_{b l}=$ Base dimension of the building in the direction of earthquake shaking

$R=$ Response reduction factor

$I=$ Importance factor

$p_{d}=$ Design wind pressure

$K_{d}=$ Wind directionality factor

$K_{a}=$ Area averaging factor

$K_{c}=$ Combination factor

$V_{z}=$ Design wind speed

$V_{b}=$ Basic wind speed

$k_{1}=$ Probability factor

$k_{2}=$ Terrain roughness and height factor

$k_{3}=$ Topology factor 
$k_{4}=$ Importance factor for cyclonic region

850

$b=$ Width of the beam

851

$D=$ Overall depth of the beam

852

$d_{e}=$ Effective depth of the beam

853

$d^{\prime}=$ depth of compression reinforcement from compression face of

854 beam.

855

$l_{c}=$ effective length of column

856

$D_{c}=$ width/ depth of the column

857

858

859

860

861

862

863

864

865

866

867

868

869

$\frac{x_{u m a x}}{d_{e}}=$ Limiting neutral axis depth factor for beam.

$f_{c k}=$ Grade of concrete

$f_{y}=$ Grade of steel reinforcement

$A_{s t}=$ Area of tensile reinforcement for beam

$A_{s c}=$ Area of compressive reinforcement for beam

$\tau_{v}=$ Nominal shear strength

$\tau_{c}=$ Shear strength of concrete

$\tau_{\text {cmax }}=$ Maximum shear strength of concrete

$s_{v}=$ Spacing of shear reinforcement for beam

$A_{s v}=$ Total cross sectional area of the stirrup legs

$a_{s}=$ Short term deflection of beam

$a_{c s}=$ Deflection of beam due to shrinkage

$a_{c c}=$ Deflection of beam due to creep 
$E_{c}=$ Short term elasticity modulus for beam

$I_{e f f}=$ Effective moment of inertia for short term deflection of beam

872

$I_{r}=$ Moment of inertia of cracked section of beam

873

$I_{g r}=$ Gross moment of inertia of beam

874

$M_{r}=$ Cracking moment

875

$f_{c r}=$ Modulus of rupture of concrete

876

877

878

879

880

881

882

883

884

885

886

887

888

889

890

$y_{t}=$ Distance from the centroidal axis of gross section, neglecting the reinforcement, to extreme fibre in tension

$M=$ Maximum moment under service load for beam

$z=$ Lever arm of the beam section

$x=$ Depth of the neutral axis for beam

$b_{w}=$ Breadth of web for beam

$b_{b}=$ Breadth of compression face for beam

$f_{3}=$ Constant depending upon the support condition of beam

$\varphi_{c s}=$ Shrinkage curvature for beam

$f_{4}=$ Factor depending on percentage of tensile and compressive reinforcement for beam

$\epsilon_{c s}=$ Ultimate shrinkage strain of concrete for beam

$l=$ Length of the span of beam

$a_{i, c c}=$ Initial plus creep deflection of beam due to permanent loads

$E_{c e}=$ Young's modulus of concrete to calculate $a_{i, c c}$ 

$E_{c}=$ Actual Young's modulus of concrete to calculate short term deflection

$\theta=$ Creep coefficient

$D_{c}=$ Depth of the column

$\mathrm{b}_{\mathrm{c}}=$ width of column

$l_{c}=$ Length of the column.

$A_{c}=$ Area of the concrete in column section

$\mathrm{A}_{\mathrm{scc}}=$ Area of reinforcement in column

$\varphi_{m}=$ Diameter of the main bar of the column

iter $=$ number of iterations in each experiment for the developed MATLAB program.

max_iter $=$ maximum number of iterations in each experiment for the developed MATLAB program.

$\exp =$ number of experiments, i.e., $1,2,3, \ldots$

nexp $=$ maximum number of experiments considered

$V_{c}=$ Volume of gross concrete work of beam / column in cubic meters.

$V_{s}=$ Volumeof steel reinforcement of beam / column in cubic meters.

$\rho_{s}=$ Density of steel i.e. $7850 \mathrm{Kg} / \mathrm{m}^{3}$

$C_{c}=$ Cost of reinforced concrete work per cubic meters.

$C_{S}=$ Cost of steel reinforcement per $\mathrm{Kg}$.

$C_{f}=$ Cost of formwork per square meters. 
Input: $S S=10, \operatorname{dim}=8\left(b, D, \varphi_{t}, \varphi_{b}, n_{c s}, n_{c m}, n_{t s}, n_{t m}\right), G M=1, M a x I t=50$, nexp $=10, S_{\min }=$ $\left[b_{\text {min }}, D_{\text {min }}, \varphi_{\text {min }}, \varphi_{\text {min }}, n_{\text {min }}, n_{\text {min }}, n_{\text {min }}, n_{\min }\right], S_{\max }=$ $\left[b_{\max }, D_{\max }, \varphi_{\max }, \varphi_{\max }, n_{\max }, n_{\max }, n_{\max }, n_{\max }\right]$

Output: Optimized variable $S_{\text {opt,beam }}$, Optimized cost $F_{\text {opt,beam }}$

1: $\quad$ for $E x=1:$ exp

2: Initialization: $t \leftarrow 0$

3: Initialization: Swarm position $S(t): b \in\left[b_{\min }, b_{\max }\right], D \in\left[D_{\min }, D_{\max }\right]$ $\varphi_{t}, \varphi_{b} \in \varphi, \varphi=[12,16,20,25,32], \varphi_{t}, \varphi_{b} \in\left[\varphi_{\min }, \varphi_{\max }\right], n_{c s}, n_{c m}, n_{t s}, n_{t m} \in\left[n_{\min }, n_{\max }\right]$ Swarm velocity: $H(t) \in\left[-H_{\max }, H_{\max }\right]$

4: $\quad$ Maintain: Constraint for beam design of Section 2.3.2

5: Perform: Beam design (flexure and shear), deflection check (Section 2.2.1)

6: Calculate: Cost of beam $F_{\text {beam }}$ (Eq. 38 )

7: $\quad$ Calculate: best positions $p(t), g(t)$ and $l(t)$

8: Calculate: best particle $x_{\text {opt,beam }}$, corresponding objective function $f_{\text {xopt,beam }}$ 9: Initialization: $S T O P=0$

10: $\quad$ while $S T O P=0$ do

11: Update: $t \leftarrow t+1$

12: Calculate: $\mu(t)($ Eq.37)

13: Update: $H(t)$ (Eq.34)and $S(t)$ (Eq.33)

14: Maintain: Constraint for beam design of Section 2.3.2

15: Perform: Beam design (flexure and shear), deflection check (Section 2.2.1)

16: Calculate:Cost of beam $F_{\text {beam }}$ (Eq.38)

17: Update: $p(t), g(t)$ and $l(t)$

18: Update: $x_{\text {opt, beam }} f_{\text {xopt, beam }}$

19: $\quad$ if $f_{\text {xopt }} \leq$ GMort $=$ MaxIt then

20: $\quad S T O P=1$

21: else

22: Gotostep11

23: end if

24: end while

25: Calculate: Optimize variable $S_{\text {opt }}$, Optimized $\operatorname{cost} F_{\text {xopt }}$

26: end for

27: Calculate: Final Optimize variable $S_{\text {opt,beam }}$, Optimized cost $F_{\text {xopt,beam }}$ (best out of nexp experiments) 
Algorithm2 Column design optimization

Input: $S S=10, \operatorname{dim}=6\left(b_{c}, D_{c}, k_{x}, k_{y}, \varphi_{m}, n\right), G M=1$, MaxIt $=50$, nexp $=10, S_{\min }=$ $\left[b_{c, \min }, D_{c, \min }, k_{x, \min }, k_{y, \min }, \varphi_{\min }, n_{\min }\right], S_{\max }=\left[b_{c, \max }, D_{c, \max }, k_{x, \max }, k_{y, \max }, \varphi_{\max }, n_{\max }\right]$

1: $\quad$ for $E x=1:$ exp

2: Initialization: $t \leftarrow 0$

3: Initialization:Swarmposition $S(t)$ :

$b_{c} \in\left[b_{c, \min }, b_{c, \max }\right], D_{c} \in\left[D_{c, \min }, D_{c, \max }\right], k_{x} \in\left[k_{x, \min }, k_{x, \max }\right], k_{y} \in\left[k_{y, \min }, k_{y, \max }\right]$ $\varphi_{m} \in \varphi, \varphi=[12,16,20,25,32], \varphi_{m} \in\left[\varphi_{\min }, \varphi_{\max }\right], n \in\left[n_{\min }, n_{\max }\right]$

\section{Swarm velocity $H(t) \in\left[-H_{\max }, H_{\max }\right]$}

4: Maintain: Constraint for column design of Section 2.3.2

5: Perform: Column design for longitudinal reinforcement and lateral ties (Section 2.2.2)

6: Calculate: Cost of column $F_{\text {column }}$ (Eq.38)

7: Calculate: best positions $p(t), g(t)$ and $l(t)$

8: Calculate: best particle $x_{\text {opt,column }}$, corresponding obje c tive function $f_{\text {xopt,column }}$

9: Initialization: $S T O P=0$

10: $\quad$ while $S T O P=0$ do

11: Update: $t \leftarrow t+1$

12: Calculate: $\mu(t)$ (Eq.37)

13: $\quad$ Update: $H(t)$ (Eq.34) and $S(t)$ (Eq.33)

14: Maintain: Constraint for column design of Section 2.3.2

15: Perform: Column design for longitudinal reinforcement and lateral ties (Section 2.2.2)

16: Calculate: Cost of column $F_{\text {column }}$ (Eq.38)

17: Update: $p(t), g(t)$ and $l(t)$

18: Update: $x_{\text {opt,column }}, f_{\text {xopt,column }}$

19: if $f_{\text {xopt }} \leq$ GMort=MaxIt then

20: $\quad S T O P=1$

21: else

22: Gotostep11

23: end if

24: end while

25: Calculate: Optimize variable $S_{\text {opt }}$, Optimized cost $F_{\text {xopt }}$

\section{6: end for}

27: Calculate: Final Optimize variable $S_{\text {opt,column }}$, Optimized cost $F_{\text {xopt,column }}$ (best out of nexp experiments) 
Algorithm3 Combined optimized cost of frame

Input: $X_{\min }, X_{\max }$ (as per Section.3.4), Design forces: Moment and shear force for beams, Axial forces and biaxial moments for columns from STAAD

Output: Optimized designs: $X_{\text {opt,beam }}, X_{\text {opt,column }}$, Optimized cost: $F_{\text {opt,beam }}, F_{\text {opt,column }}$

1: Beam design optimization (Algorithm 1): One by one from ground floor to top floor. Update $X_{\min , X} X_{\max }$ for each floor (Section 3.3).

2: Column design optimization (Algorithm 2): One by one from top floor to ground floor. Update $X_{\min }, X_{\max }$ for each floor (Section 3.3).

3: Find out optimum beam design and column design

3: Calculate total optimize cost of frame $=\sum F_{\text {opt, beam }}+\sum F_{\text {opt }, \text { column }}$ 
1031

1032

1033

1034

1035

1036

1037

1038

1039

1040

1041

1042

1043

1044

1045

1046

1047

\section{APPENDIX III}

Parameters used in design of beam:

For doubly reinforced beam

Table I Stress in compression reinforcement $\left(f_{s c}\right),\left(\mathrm{N} / \mathrm{mm}^{2}\right)$ in doubly reinforced beams with cold worked bars

\begin{tabular}{ccc}
\hline \hline \multicolumn{3}{c}{ SP16 Table F } \\
\hline$d^{\prime} / d$ & $f_{y}=415 \mathrm{~N} / \mathrm{mm}^{2}$ & $f_{y}=500 \mathrm{~N} / \mathrm{mm}^{2}$ \\
\hline 0.05 & 355 & 424 \\
0.1 & 353 & 412 \\
0.15 & 342 & 395 \\
0.2 & 329 & 370 \\
\hline \hline
\end{tabular}

For design of beam in shear

Design shear strength $\tau_{c}=\frac{0.85 \sqrt{0.8 f_{c k}}(\sqrt{1+5 \beta}-1)}{6 \beta}, \beta=\frac{0.8 f_{c k}}{6.89 P_{t}} \geq 1, P_{t}=\frac{100 A_{s t}}{b d}, A_{s t}$ is area of tensile reinforcement, $b, d$ are width and effective depth. $f_{c k}=$ Grade of concrete

Table II Maximum Shear Stress $\left(\tau_{c, \max }\right), \mathrm{N} / \mathrm{mm}^{2}$ (IS 456)

Table 24 (Clauses B-2.3, B-5.2.3. B·5.2.3. t, B.5.5,1 and B-

6.3.1)

\begin{tabular}{|c|c|c|c|c|c|c|}
\hline$f_{c k}\left(\mathrm{~N} / \mathrm{mm}^{2}\right)$ & 15 & 20 & 25 & 30 & 35 & 40 \\
\hline$\tau_{c, \max }\left(\mathrm{N} / \mathrm{mm}^{2}\right)$ & 2.5 & 2.8 & 3.1 & 3.5 & 3.7 & 4 \\
\hline
\end{tabular}

For deflection check in beam

$f_{3}=0.5$ for cantilevers, 0.125 for simply supported members, 0.086 for continuous at one end and 0.063 for fully continuous members

$f_{4}=0.72 \frac{P_{t}-P_{c}}{\sqrt{P_{t}}} \leq 1.0$ for $0.25 \leq P_{t}-P_{c} \leq 1.0$

$=0.65 \frac{P_{t}-P_{c}}{\sqrt{P_{t}}} \leq 1.0$ for $P_{t}-P_{c} \geq 1.0, P_{t}=\frac{100 A_{s t}}{b d}, P_{c}=\frac{100 A_{s c}}{b d}, A_{s c}$ is area of compressive reinforcement.

\section{Parameters used in design of column:}

Table III Salient points on the design stress-strain curve for cold-worked bars

\begin{tabular}{cccc}
\hline \hline \multicolumn{4}{c}{ SP 16 $($ Table A) } \\
\hline \multicolumn{2}{c}{$f_{y}=415 \mathrm{~N} / \mathrm{mm}^{2}$} & \multicolumn{2}{c}{$f_{y}=500 \mathrm{~N} / \mathrm{mm}^{2}$} \\
\hline Strain & Stress $\left(\mathrm{N} / \mathrm{mm}^{2}\right)$ & Strain & Stress $\left(\mathrm{N} / \mathrm{mm}^{2}\right)$ \\
\hline 0.00144 & 288.7 & 0.00174 & 347.8 \\
0.00163 & 306.7 & 0.00195 & 369.6 \\
0.00192 & 324.8 & 0.00226 & 391.3 \\
0.00241 & 342.8 & 0.00277 & 413 \\
0.00276 & 351.8 & 0.00312 & 423.9 \\
0.0038 & 360.9 & 0.00417 & 434.8 \\
\hline \hline
\end{tabular}


Parameters used in wind analysis:

Table IV Risk coefficient $\left(k_{1}\right)$ for structures in different wind speed zones

\begin{tabular}{|c|c|c|c|c|c|c|c|}
\hline \multicolumn{10}{|c|}{ IS 875 part 32015 Table 1 (Clause 6.3.1) } \\
\hline \multirow{2}{*}{ Class of structures } & \multirow{2}{*}{$\begin{array}{c}\text { Design life of } \\
\text { structures (years) }\end{array}$} & \multicolumn{7}{|c|}{$k_{1}$ factor for basic wind speed (m/s) } \\
\cline { 3 - 9 } & 33 & 39 & 44 & 47 & 50 & 55 \\
\hline All general structures & 50 & 1.00 & 1.00 & 1.00 & 1.00 & 1.00 & 1.00 \\
\hline Temporary structures & 5 & 0.82 & 0.76 & 0.73 & 0.71 & 0.70 & 0.67 \\
\hline $\begin{array}{c}\text { Structures with low degree } \\
\text { of hazards }\end{array}$ & 25 & 0.94 & 0.92 & 0.91 & 0.90 & 0.90 & 0.89 \\
\hline Important building & 100 & 1.05 & 1.06 & 1.07 & 1.07 & 1.08 & 1.08 \\
\hline
\end{tabular}

Table V Factors to obtain design wind speed variation with height in different terrains $\left(k_{2}\right)$

\begin{tabular}{|c|c|c|c|c|}
\hline \multicolumn{5}{|c|}{ IS 875 part 32015 Table 2 (Clause 6.3.2.2.) } \\
\hline \multirow[t]{2}{*}{$\begin{array}{l}\text { Height } \\
\text { (m) }\end{array}$} & \multicolumn{4}{|c|}{ Height multiplier $\left(k_{2}\right)$ for terrain } \\
\hline & 1 & 2 & 3 & 4 \\
\hline 10 & 1.05 & 1.00 & 0.91 & 0.80 \\
\hline 15 & 1.09 & 1.05 & 0.97 & 0.80 \\
\hline 20 & 1.12 & 1.07 & 1.01 & 0.80 \\
\hline 30 & 1.15 & 1.12 & 1.06 & 0.97 \\
\hline 50 & 1.2 & 1.17 & 1.12 & 1.1 \\
\hline 100 & 1.26 & 1.24 & 1.2 & 1.2 \\
\hline 150 & 1.3 & 1.28 & 1.24 & 1.24 \\
\hline 200 & 1.32 & 1.3 & 1.27 & 1.27 \\
\hline 250 & 1.34 & 1.32 & 1.29 & 1.28 \\
\hline 300 & 1.35 & 1.34 & 1.31 & 1.3 \\
\hline 350 & 1.35 & 1.35 & 1.32 & 1.31 \\
\hline 400 & 1.35 & 1.35 & 1.34 & 1.32 \\
\hline 450 & 1.35 & 1.35 & 1.35 & 1.33 \\
\hline 500 & 1.35 & 1.35 & 1.35 & 1.34 \\
\hline
\end{tabular}


1058

1059

1060

1061

1062

1063

1064

1065

1066

1067

1068

1069

1070

1071

1072

1073

1074

1075

1076

\section{List of Tables}

1 Review of all the optimization techniques used by the researchers for solving design optimization problem of RC structures

2 Beam design details for three different floors - L shaped building frame .45

3 Typical column design details for all floor - $\mathrm{L}$ shaped building frame............46

4 Beam design details for three different floors- U shaped building frame. .47

$5 \quad$ Typical column design details for all floor $-\mathrm{U}$ shaped building frame. .48

6 Monte Carlo Result summary (L shaped frame)

7 Monte Carlo Result summary (U shaped frame)

8 MATLAB and STAADPro comparison of beam design (L shaped frame)

9 MATLAB and STAADPro comparison of column design (L shaped frame)

10 MATLAB and STAADPro comparison of beam design (U shaped frame)

11 MATLAB and STAADPro comparison of column design (U shaped frame) 
Table 1. Review of all the optimization techniques used by the researchers for solving design optimization problem of RC structures

\begin{tabular}{ll}
\hline \hline \multicolumn{1}{c}{ Authors } & \multicolumn{1}{c}{ Optimization algorithm } \\
\hline Prakash et al.[7] & $\begin{array}{l}\text { Simplex and Lagrangian optimization } \\
\text { method }\end{array}$ \\
\hline Chakrabarty [8] & Geometric programming \\
\hline $\begin{array}{l}\text { Coello et al.[9], Rajeev and } \\
\text { Krishnamoorthy[10], Chaudhuri and Maity[20] }\end{array}$ & Genetic algorithm (GA) \\
\hline Dole et al. [11] & polynomial optimization technique \\
\hline De Medeiros et al. [12] & Simulated annealing (SA) \\
\hline Nigdeli and Bekdaş [13] & random search technique (RST) \\
\hline Uz et al. [14], Kaveh and Behnam [21] & charged system search (CSS) \\
\hline Preethi and Arulraj [16] & sequential quadratic programming (SQP) \\
\hline Bekdaş and Niğdeli [17] & $\begin{array}{l}\text { Teaching-learning-based-optimization } \\
\text { (TLBO) }\end{array}$ \\
\hline Bekdaş and Nigdel[22] & Harmony search (HS) \\
\hline Aga and Adam[23] & Artificial neural network (ANN) \\
\hline Gharehbaghi and Khatibinia[24] & $\begin{array}{l}\text { intelligent regression model (IRM) } \\
\text { combined with Particle swarm optimization }\end{array}$ \\
& (PSO) \\
\hline Esfandiary et al. [25, 29] & $\begin{array}{l}\text { decision-making Particle Swarm } \\
\text { Optimization (DMPSO) }\end{array}$ \\
\hline Kulkarni and Bhusare[26] & Response Surface Method (RSM) \\
\hline Tapao and Cheerarot[28] & Artificial bee colony (ABC) \\
\hline RazmaraShooli et al. [30] & GA-PSO algorithm \\
\hline Chaudhuri and Maity [20] & $\begin{array}{l}\text { Unified particle swarm optimization } \\
\text { (UPSO) }\end{array}$ \\
\hline \hline &
\end{tabular}


Tables 2 Beam design details for three different floors - L shaped building frame.

\begin{tabular}{|c|c|c|c|c|c|c|c|}
\hline \multirow{2}{*}{ Floors } & \multirow{2}{*}{$\begin{array}{l}\text { Beam } \\
\text { types }\end{array}$} & \multirow{2}{*}{$\begin{array}{l}\text { Size }(\mathrm{mm} x \\
\mathrm{mm})\end{array}$} & \multicolumn{2}{|c|}{ Support (mm) } & \multicolumn{2}{|c|}{ Mid-span (mm) } & \multirow{2}{*}{$\begin{array}{l}\begin{array}{l}\text { Stirrups } \\
\text { spacing }\end{array} \\
8 \mathrm{~mm} \varphi\end{array}$} \\
\hline & & & Top & Bottom & Top & Bottom & \\
\hline \multirow{3}{*}{ Top } & B1 & $210 \times 410$ & $3-12 \varphi$ & $3-12 \varphi$ & $2-12 \varphi$ & $3-12 \varphi$ & 300 \\
\hline & $\begin{array}{c}\text { B2, } \\
\text { B3,B4 }\end{array}$ & $210 \times 420$ & $2-16 \varphi$ & $2-12 \varphi$ & $2-16 \varphi$ & $3-12 \varphi$ & 300 \\
\hline & B5 & $210 \times 420$ & $3-12 \varphi$ & $3-12 \varphi$ & $2-12 \varphi$ & $3-12 \varphi$ & 300 \\
\hline \multirow{4}{*}{ 6th } & B1 & $210 \times 390$ & $3-20 \varphi$ & $2-20 \varphi$ & $2-20 \varphi$ & $2-20 \varphi$ & 300 \\
\hline & B2, B3 & $270 \times 530$ & $6-16 \varphi$ & 2- $20 \varphi$ & $2-16 \varphi$ & $2-20 \varphi$ & 300 \\
\hline & B4 & $240 \times 470$ & 4- $20 \varphi$ & $2-20 \varphi$ & $2-20 \varphi$ & 3- $20 \varphi$ & 300 \\
\hline & B5 & $240 \times 470$ & $5-16 \varphi$ & $2-20 \varphi$ & $2-16 \varphi$ & 3- $20 \varphi$ & 300 \\
\hline \multirow{5}{*}{$1 \mathrm{st}$} & B1 & $240 \times 460$ & $5-20 \varphi$ & $2-20 \varphi$ & $2-20 \varphi$ & $3-20 \varphi$ & 300 \\
\hline & B2 & $280 \times 530$ & $6-16 \varphi$ & $2-20 \varphi$ & $2-16 \varphi$ & 4- $20 \varphi$ & 300 \\
\hline & B3 & $270 \times 510$ & $5-20 \varphi$ & $2-20 \varphi$ & $2-20 \varphi$ & 4- $20 \varphi$ & 300 \\
\hline & B4 & $270 x 520$ & 5- $20 \varphi$ & 3- $20 \varphi$ & $2-20 \varphi$ & $2-20 \varphi$ & 300 \\
\hline & B5 & $240 \times 470$ & $5-20 \varphi$ & $2-20 \varphi$ & 2- $20 \varphi$ & $3-20 \varphi$ & 300 \\
\hline
\end{tabular}


Table 3.TypicalColumndesign details for all floor - $\mathrm{L}$ shaped building frame.

\begin{tabular}{lllllllll}
\hline \hline \multirow{2}{*}{$\begin{array}{l}\text { Floor } \\
\mathrm{s}\end{array}$} & \multicolumn{2}{c}{$\mathrm{C} 1$} & \multicolumn{9}{c}{ Column numbers } \\
\cline { 2 - 9 } & $\begin{array}{l}\text { Size } \\
(\mathrm{mmxmm})\end{array}$ & $\begin{array}{l}\text { Reinforc } \\
\text { ement }\end{array}$ & $\begin{array}{l}\text { Size } \\
(\mathrm{mmxmm})\end{array}$ & $\begin{array}{l}\text { Reinfor } \\
\text { cement }\end{array}$ & $\begin{array}{l}\text { Size } \\
(\mathrm{mmxmm})\end{array}$ & $\begin{array}{l}\text { Reinfor } \\
\text { cement }\end{array}$ & $\begin{array}{l}\text { Size } \\
(\mathrm{mmxmm})\end{array}$ & $\begin{array}{c}\text { Reinforc } \\
\text { ement }\end{array}$ \\
\hline 8 & $340 \times 450$ & $12-16 \varphi$ & $320 \times 380$ & $8-16 \varphi$ & $370 \times 280$ & $8-16 \varphi$ & $430 \times 370$ & $8-12 \varphi$ \\
7 & $410 \times 450$ & $12-16 \varphi$ & $330 \times 420$ & $8-20 \varphi$ & $380 \times 330$ & $8-20 \varphi$ & $450 \times 450$ & $8-12 \varphi$ \\
6 & $440 \times 450$ & $12-16 \varphi$ & $350 \times 440$ & $8-20 \varphi$ & $410 \times 370$ & $8-20 \varphi$ & $450 \times 450$ & $8-20 \varphi$ \\
5 & $450 \times 450$ & $12-20 \varphi$ & $370 \times 450$ & $8-20 \varphi$ & $440 \times 410$ & $8-20 \varphi$ & $450 \times 450$ & $8-20 \varphi$ \\
4 & $450 \times 450$ & $12-20 \varphi$ & $410 \times 500$ & $8-20 \varphi$ & $450 \times 430$ & $8-20 \varphi$ & $450 \times 450$ & $8-20 \varphi$ \\
3 & $460 \times 480$ & $12-20 \varphi$ & $420 \times 500$ & $8-20 \varphi$ & $480 \times 460$ & $8-20 \varphi$ & $470 \times 470$ & $8-20 \varphi$ \\
2 & $500 \times 500$ & $12-20 \varphi$ & $470 \times 500$ & $8-20 \varphi$ & $490 \times 500$ & $8-20 \varphi$ & $500 \times 500$ & $8-20 \varphi$ \\
1 & $500 \times 500$ & $12-20 \varphi$ & $500 \times 500$ & $8-20 \varphi$ & $500 \times 500$ & $8-20 \varphi$ & $500 \times 500$ & $8-20 \varphi$ \\
$G$ & $500 \times 500$ & $12-20 \varphi$ & $500 \times 500$ & $8-25 \varphi$ & $500 \times 500$ & $8-25 \varphi$ & $500 \times 500$ & $8-25 \varphi$ \\
\hline \hline
\end{tabular}


Table 4.Beam design details for three different floors- U shaped building frame

\begin{tabular}{|c|c|c|c|c|c|c|c|}
\hline \multirow{2}{*}{ Floors } & \multirow{2}{*}{ Beam types } & \multirow{2}{*}{$\begin{array}{l}\text { Size (mm } \\
\text { x mm) }\end{array}$} & \multicolumn{2}{|c|}{ Support (mm) } & \multicolumn{2}{|c|}{ Mid-span (mm) } & \multirow{2}{*}{$\begin{array}{c}\begin{array}{r}\text { Stirrups } \\
\text { spacing }\end{array} \\
8 \mathrm{~mm} \varphi\end{array}$} \\
\hline & & & Top & Bottom & Top & Bottom & \\
\hline Top & $\begin{array}{c}\text { B1,B2, B3, } \\
\text { B4, B5, } \\
\text { B6, B7, B8 }\end{array}$ & $200 \times 380$ & $2-12 \varphi$ & $2-16 \varphi$ & $2-12 \varphi$ & $2-16 \varphi$ & 300 \\
\hline \multirow{6}{*}{ 9th } & B1 & $220 \times 430$ & $5-12 \varphi$ & $2-16 \varphi$ & $2-12 \varphi$ & $3-16 \varphi$ & 300 \\
\hline & B2, B3 & $220 x 440$ & $5-12 \varphi$ & $2-16 \varphi$ & $2-12 \varphi$ & $3-16 \varphi$ & 300 \\
\hline & B4 & $230 \times 450$ & $5-12 \varphi$ & $2-16 \varphi$ & $2-12 \varphi$ & $3-16 \varphi$ & 300 \\
\hline & B5 & $220 \times 430$ & 4- $16 \varphi$ & $2-16 \varphi$ & $2-16 \varphi$ & $3-16 \varphi$ & 300 \\
\hline & B6, B7 & $200 \times 370$ & 4- $16 \varphi$ & $2-16 \varphi$ & $2-16 \varphi$ & $2-16 \varphi$ & 300 \\
\hline & B8 & $220 \times 350$ & 4- $16 \varphi$ & $2-16 \varphi$ & $2-16 \varphi$ & $3-16 \varphi$ & 300 \\
\hline \multirow{8}{*}{$1 \mathrm{st}$} & B1 & $240 \times 470$ & $5-16 \varphi$ & $3-16 \varphi$ & $2-16 \varphi$ & $4-16 \varphi$ & 300 \\
\hline & B2 & $240 \times 480$ & 4- $16 \varphi$ & 2- $16 \varphi$ & $2-16 \varphi$ & $3-16 \varphi$ & 300 \\
\hline & B3 & $250 \times 480$ & 4- $16 \varphi$ & $2-16 \varphi$ & $2-16 \varphi$ & $4-16 \varphi$ & 300 \\
\hline & B4 & $230 \times 450$ & 5- $16 \varphi$ & $3-16 \varphi$ & $2-16 \varphi$ & $3-16 \varphi$ & 300 \\
\hline & B5 & $250 \times 500$ & 4- $16 \varphi$ & $2-16 \varphi$ & $2-16 \varphi$ & $4-16 \varphi$ & 300 \\
\hline & B6 & $240 \times 430$ & $5-16 \varphi$ & $3-16 \varphi$ & $2-16 \varphi$ & $3-16 \varphi$ & 300 \\
\hline & B7 & $240 \times 440$ & 5- $16 \varphi$ & $3-16 \varphi$ & $2-16 \varphi$ & $3-16 \varphi$ & 300 \\
\hline & B8 & $240 \times 470$ & $5-16 \varphi$ & $3-16 \varphi$ & $2-16 \varphi$ & $3-16 \varphi$ & 300 \\
\hline
\end{tabular}


Table 5.Typicalcolumn design details for all floor $-\mathrm{U}$ shaped building frame

\begin{tabular}{ccccccccc}
\hline & \multicolumn{7}{c}{ Column numbers } \\
\cline { 2 - 8 } Floors & \multicolumn{2}{c}{ C1 } & \multicolumn{2}{c}{ C3 } & \multicolumn{2}{c}{ C5 } & \multicolumn{2}{c}{ C9 } \\
\cline { 2 - 8 } & $\begin{array}{c}\text { Size } \\
(\mathrm{mmxm} \\
\mathrm{m})\end{array}$ & $\begin{array}{c}\text { Reinfor } \\
\text { cement }\end{array}$ & $\begin{array}{c}\text { Size } \\
(\mathrm{mmxmm} \\
\end{array}$ & $\begin{array}{c}\text { Reinforc } \\
\text { ement }\end{array}$ & $\begin{array}{c}\text { Size } \\
(\mathrm{mmxmm} \\
)\end{array}$ & $\begin{array}{c}\text { Reinforc } \\
\text { ement }\end{array}$ & $\begin{array}{c}\text { Size } \\
(\mathrm{mmxmm} \\
)\end{array}$ & $\begin{array}{c}\text { Reinforc } \\
\text { ement }\end{array}$ \\
\hline 10 & $330 \times 320$ & $4-12 \varphi$ & $330 \times 260$ & $4-12 \varphi$ & $270 \times 310$ & $4-12 \varphi$ & $310 \times 310$ & $4-12 \varphi$ \\
9 & $380 \times 350$ & $4-16 \varphi$ & $350 \times 360$ & $4-12 \varphi$ & $330 \times 350$ & $4-16 \varphi$ & $390 \times 320$ & $4-16 \varphi$ \\
8 & $390 \times 370$ & $4-20 \varphi$ & $390 \times 370$ & $4-20 \varphi$ & $350 \times 370$ & $4-20 \varphi$ & $400 \times 380$ & $4-20 \varphi$ \\
7 & $400 \times 390$ & $4-20 \varphi$ & $400 \times 380$ & $4-20 \varphi$ & $360 \times 390$ & $4-20 \varphi$ & $400 \times 390$ & $4-20 \varphi$ \\
6 & $400 \times 400$ & $4-20 \varphi$ & $400 \times 400$ & $4-20 \varphi$ & $380 \times 400$ & $4-20 \varphi$ & $400 \times 400$ & $4-20 \varphi$ \\
5 & $400 \times 400$ & $4-20 \varphi$ & $400 \times 400$ & $4-20 \varphi$ & $390 \times 400$ & $8-20 \varphi$ & $400 \times 400$ & $4-20 \varphi$ \\
4 & $400 \times 400$ & $4-20 \varphi$ & $400 \times 400$ & $4-20 \varphi$ & $390 \times 400$ & $8-20 \varphi$ & $400 \times 400$ & $4-20 \varphi$ \\
3 & $400 \times 400$ & $4-20 \varphi$ & $400 \times 400$ & $4-20 \varphi$ & $390 \times 400$ & $8-20 \varphi$ & $400 \times 400$ & $4-20 \varphi$ \\
2 & $400 \times 400$ & $4-20 \varphi$ & $400 \times 400$ & $8-20 \varphi$ & $400 \times 400$ & $8-20 \varphi$ & $400 \times 400$ & $8-20 \varphi$ \\
1 & $400 \times 400$ & $4-20 \varphi$ & $400 \times 400$ & $8-20 \varphi$ & $400 \times 400$ & $8-20 \varphi$ & $400 \times 400$ & $8-20 \varphi$ \\
$\mathrm{G}$ & $400 \times 400$ & $8-20 \varphi$ & $400 \times 400$ & $8-20 \varphi$ & $400 \times 400$ & $8-20 \varphi$ & $400 \times 400$ & $8-20 \varphi$ \\
\hline \hline
\end{tabular}


Table 6. Monte Carlo Result summary (L shaped framed)

\begin{tabular}{lrrrr}
\hline \hline \multicolumn{5}{c}{ RESULT SUMMARY } \\
\hline \\
\hline
\end{tabular}

MONTE CARLO simulation

\begin{tabular}{lllll}
\hline First simulation & 1033501.77 & 875617.80 & 1934664.40 & $\mathbf{3 8 8 5 0 4 4 . 1 3}$
\end{tabular}

After 5000 Simulation

\section{Total cost (Rs.)}

Mean

3856471.18

Standard Deviation (S)

22264.92

Min

3792373.03

$\operatorname{Max}$

3923637.97

Difference

131264.93

Increment

6563.24

Design failure

0

Key Percentile

\begin{tabular}{rrr}
\hline & $\mathbf{2 5 \%}$ & $\mathbf{3 8 4 1 8 5 8 . 2 1}$ \\
& $\mathbf{5 0 \%}$ & $\mathbf{3 8 5 6 8 2 2 . 1 5}$ \\
& $\mathbf{7 5 \%}$ & $\mathbf{3 8 7 2 0 0 5 . 0 2}$ \\
& $\mathbf{9 9 \%}$ & $\mathbf{3 9 2 6 5 6 8 . 3 6}$ \\
Loss percentile & & 2 \\
\hline \hline
\end{tabular}

1091

1092 
Table 7. Monte Carlo Result summary (U shaped framed)

\begin{tabular}{|c|c|c|c|c|}
\hline \multicolumn{5}{|c|}{ Result Summary } \\
\hline \multicolumn{5}{|c|}{ Results after 10 number of experiments } \\
\hline & $\begin{array}{l}\text { Total } \\
\text { concrete }\end{array}$ & $\begin{array}{l}\text { Total } \\
\text { formwork }\end{array}$ & Total steel & Total cost \\
\hline & Rs. & Rs. & Rs. & Rs. \\
\hline Mean & 830104.70 & 751285.78 & 1277901.51 & 2859292.00 \\
\hline Standard Deviation $(\mathrm{S})$ & 4042.70 & 2251.79 & 6651.91 & 9282.60 \\
\hline Max value & 836727.36 & 754809.66 & 1287597.09 & 2875499.09 \\
\hline Min value & 824728.59 & 747885.6 & 1270301.75 & 2847013.56 \\
\hline \multicolumn{5}{|c|}{ MONTE CARLO simulation } \\
\hline First simulation & 820513.55 & 754301.59 & 1272679.41 & 2863711.65 \\
\hline \multicolumn{5}{|c|}{ After 5000 Simulation } \\
\hline \multicolumn{2}{|c|}{ Total cost (Rs.) } & & & \\
\hline Mean & 2859591.13 & & & \\
\hline Standard Deviation $(\mathrm{S})$ & 7680.10 & & & \\
\hline Min & 2833889.28 & & & \\
\hline Max & 2887321.15 & & & \\
\hline Difference & 53431.86 & & & \\
\hline Increment & 2671.59 & & & \\
\hline Design failure & 0 & & & \\
\hline \multicolumn{5}{|c|}{ Key Percentile } \\
\hline $25 \%$ & 2853784.32 & & & \\
\hline $50 \%$ & 2859260.04 & & & \\
\hline $75 \%$ & 2864541.17 & & & \\
\hline $99 \%$ & 2881806.97 & & & \\
\hline Loss percentile & 0.6 & & & \\
\hline
\end{tabular}

1094

1095 
Table 8.Comparison of beam design forces before and after optimization(L shaped frame)

\begin{tabular}{|c|c|c|c|c|c|c|}
\hline \multirow{2}{*}{$\begin{array}{l}\text { Fourth } \\
\text { floor }\end{array}$} & \multirow{2}{*}{$\begin{array}{l}\text { Beam } \\
\text { No. }\end{array}$} & \multirow{2}{*}{$\begin{array}{l}\text { Size }(\mathrm{mm} \\
\mathrm{x} \mathrm{mm})\end{array}$} & \multicolumn{3}{|c|}{$\begin{array}{c}\text { Bending moment } \\
(\mathrm{kN}-\mathrm{m})\end{array}$} & \multirow{2}{*}{$\begin{array}{l}\text { Shear } \\
\text { force } \\
(\mathrm{KN})\end{array}$} \\
\hline & & & $\begin{array}{l}\text { Support } \\
\text { top }\end{array}$ & $\begin{array}{l}\text { Support } \\
\text { bottom }\end{array}$ & $\begin{array}{c}\text { Midspan } \\
\text { bottom }\end{array}$ & \\
\hline Before & \multirow{2}{*}{ B1 } & & 249 & 117 & 51 & 155 \\
\hline After & & $270 \times 530$ & 233 & 111 & 50 & 144 \\
\hline Before & \multirow{2}{*}{ B2 } & & 255 & 130 & 50 & 150 \\
\hline After & & $280 \times 490$ & 242 & 122 & 60 & 144 \\
\hline Before & \multirow{2}{*}{ B3 } & & 260 & 133 & 61 & 152 \\
\hline After & & $240 \times 400$ & 243 & 125 & 60 & 144 \\
\hline Before & \multirow{2}{*}{ B4 } & & 263 & 137 & 61 & 153 \\
\hline After & & $240 \times 440$ & 260 & 143 & 64 & 144 \\
\hline Before & \multirow{2}{*}{ B5 } & & 260 & 131 & 60 & 153 \\
\hline After & & $220 \times 430$ & 260 & 130 & 54 & 144 \\
\hline
\end{tabular}

1097

1098 
1099 Table 9.Comparison of column design forces before and after optimization(L shaped frame)

\begin{tabular}{|c|c|c|c|c|c|}
\hline \multirow{2}{*}{$\begin{array}{l}\text { Fourth } \\
\text { floor }\end{array}$} & \multirow{2}{*}{$\begin{array}{c}\text { Column } \\
\text { No. }\end{array}$} & \multirow{2}{*}{$\begin{array}{l}\text { Size }(\mathrm{mm} x \\
\mathrm{mm})\end{array}$} & \multirow{2}{*}{$\begin{array}{l}\text { Axial force } \\
\qquad(\mathrm{kN})\end{array}$} & \multicolumn{2}{|c|}{$\begin{array}{c}\text { Bending momen } \\
(\mathrm{kN}-\mathrm{m})\end{array}$} \\
\hline & & & & $\mathrm{M}_{\mathrm{z}}$ & $\mathrm{M}_{\mathrm{y}}$ \\
\hline Before & \multirow{2}{*}{$\mathrm{C} 1$} & & 1587 & 254 & 9 \\
\hline After & & $450 \times 450$ & 1575 & 207 & 3 \\
\hline Before & \multirow{2}{*}{$\mathrm{C} 2$} & & 1262 & 250 & 37 \\
\hline After & & $450 \times 450$ & 1231 & 216 & 35 \\
\hline Before & \multirow{2}{*}{$\mathrm{C} 3$} & & 1125 & 41 & 184 \\
\hline After & & $450 \times 450$ & 1096 & 39 & 173 \\
\hline Before & \multirow{2}{*}{$\mathrm{C} 4$} & & 1537 & 6 & 232 \\
\hline After & & $420 \times 450$ & 1505 & 4 & 205 \\
\hline Before & \multirow{2}{*}{$\mathrm{C} 5$} & & 1565 & 1.49 & 250 \\
\hline After & & $450 \times 450$ & 1507 & 1.3 & 224 \\
\hline Before & \multirow{2}{*}{ C6 } & & 1217 & 40 & 227 \\
\hline After & & $430 \times 450$ & 1210 & 37 & 219 \\
\hline Before & \multirow{2}{*}{$\mathrm{C} 7$} & & 1523 & 221 & 6 \\
\hline After & & $450 \times 450$ & 1508 & 204 & 3.6 \\
\hline Before & \multirow{2}{*}{$\mathrm{C} 8$} & & 1262 & 181 & 40 \\
\hline After & & $400 \times 400$ & 1247 & 175 & 38 \\
\hline Before & \multirow{2}{*}{ C9 } & & 1245 & 184 & 41 \\
\hline After & & $450 \times 390$ & 1230 & 178 & 39 \\
\hline Before & \multirow{2}{*}{$\mathrm{C} 10$} & & 1123 & 148 & 39 \\
\hline After & & $450 \times 430$ & 1106 & 144 & 38 \\
\hline Before & \multirow{2}{*}{$\mathrm{C} 11$} & & 1246 & 230 & 43 \\
\hline After & & $450 \times 400$ & 1186 & 227 & 41 \\
\hline Before & \multirow{2}{*}{$\mathrm{C} 12$} & & 1110 & 220 & 43 \\
\hline After & & $450 \times 450$ & 997 & 199 & 40 \\
\hline
\end{tabular}

1100

1101 


\section{List of Figures}

1103

1104

1105

1106

1107

1108

1109

1110

1111

1112

1113

1114

1115

1116

1117

1118

1119

1120

1121

1122

1123

1124

1125

1126

1127

1128

1129

1130

1131

Typical velocity profile of wind moving through a particular terrain $\left(\mathrm{x}_{1}, \mathrm{x}_{2}=\mathrm{fetch}\right.$

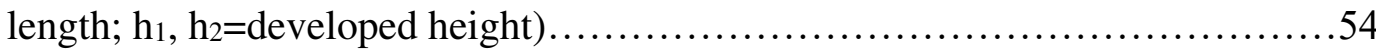

2 Design acceleration response spectrum of IS 1893-2016(Part-III) [43] .55

3 a) Typical reinforcement detail of column section b) Strain diagram of concrete section when neutral axis lies inside the section c) Strain diagram of concrete section when neutral axis lies outside the section d) Stress diagram of concrete section when neutral axis lies outside the section 56

$4 \quad$ Flowchart for cost optimization of whole frame .57

5 Formwork profile of member cross sections: a) beam b) column .58

6 Typical floor grid plan of the building frames showing beams and column positions a) $\mathrm{L}$ shaped building b) $U$ shaped building

7 Wind profile used wind load analysis a) Velocity profile b) Pressure profile....60

8 Schematic diagram of continuous beam showing the details of curtailments in bars

9 Design optimization results for L-shaped building frame. (a)convergence curve of total cost for different grade concrete along with Fe 415 steel.(b)convergence curve for cost of different parameters for M20 concrete and Fe 415 steel. (c) Variation of total cost for different concrete and steel grades

10 Design optimization results for U-shaped building frame. (a)convergence curve of total cost for different grade concrete along with Fe 415 steel.(b)convergence curve for cost of different parameters for M25 concrete and Fe 415 steel. (c) Variation of total cost for different concrete and steel grades .63

11 Probability distribution for 5000 simulated solutions (L shaped frame)

12 Probability distribution for 5000 simulated solutions (U shaped frame) 


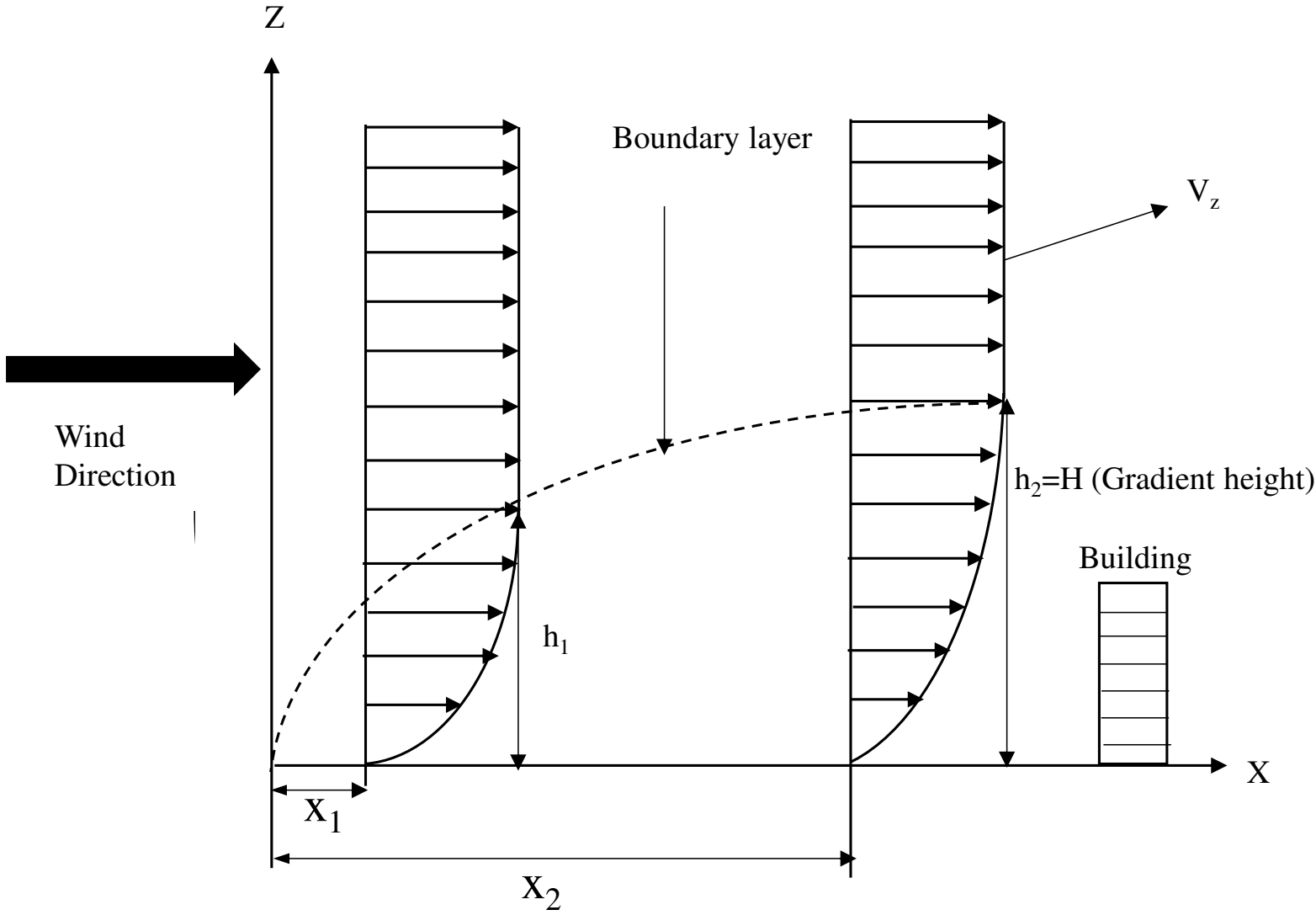

Fig.1. Typical velocity profile of wind moving through a particular terrain $\left(\mathrm{x}_{1}, \mathrm{x}_{2}=\mathrm{fetch}\right.$ length; $h_{1}, h_{2}=$ developed height) 


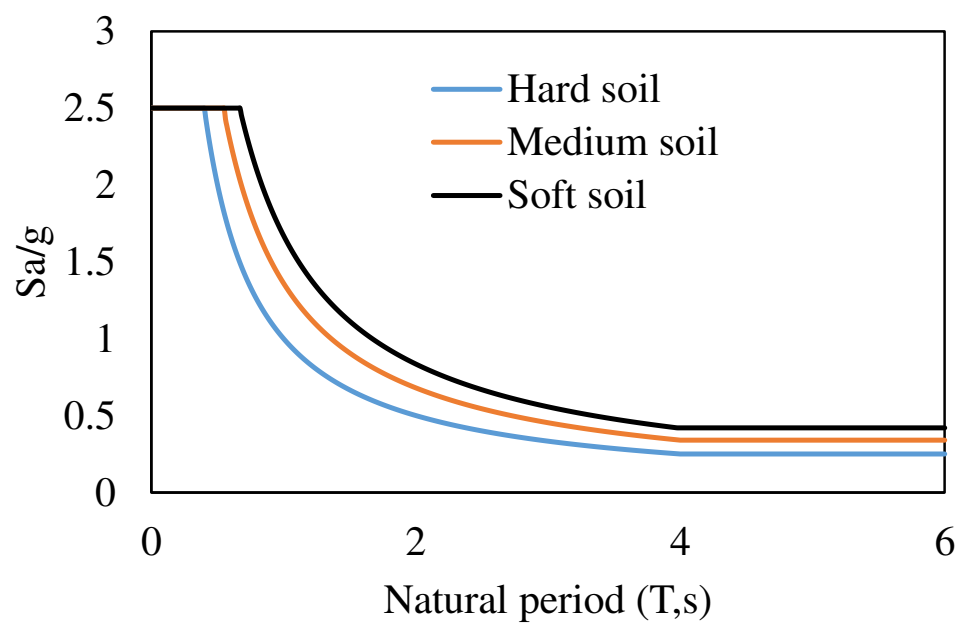

Fig.2.Design acceleration response spectrum of IS 1893-2016(Part-III)[43]

1144

1145

1146

1147 
a)

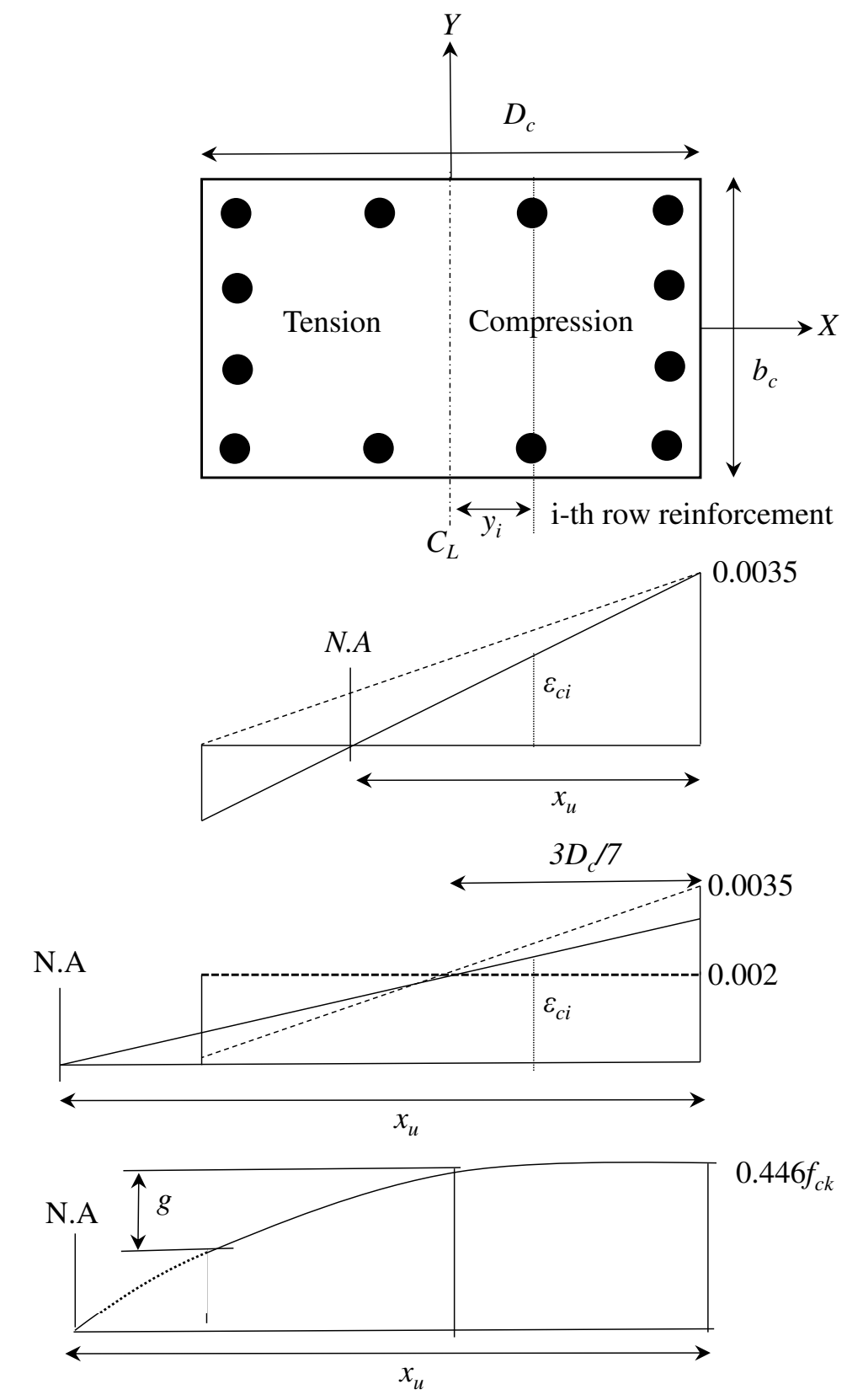

b)
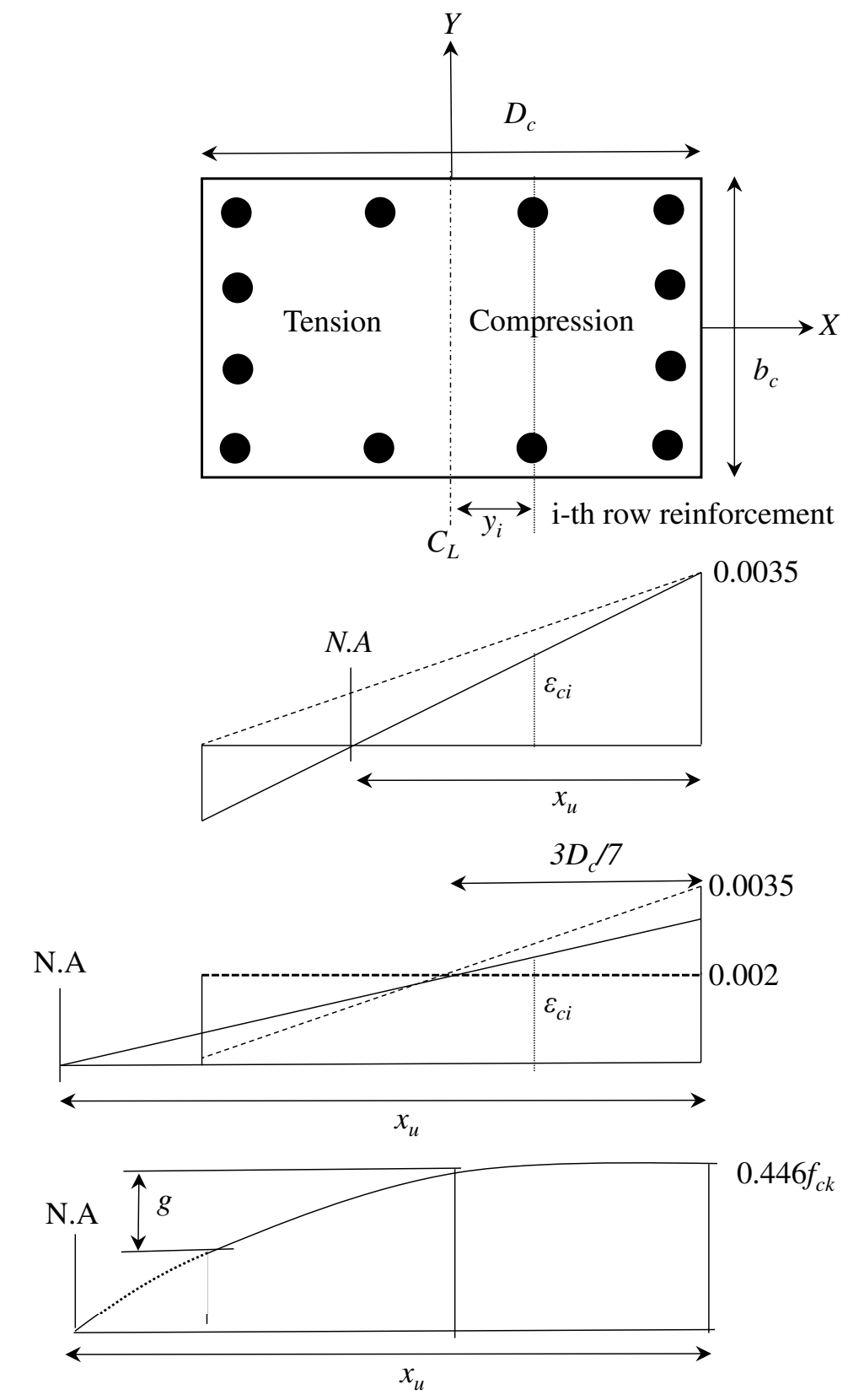

c)

1149

1150 Fig. 3.a) Typical reinforcement detail of column section b) Strain diagram of concrete section

1151 when neutral axis lies inside the section c) Strain diagram of concrete section when neutral

1152 axis lies outside the section d) Stress diagram of concrete section when neutral axis lies

1153 outside the section

1154 


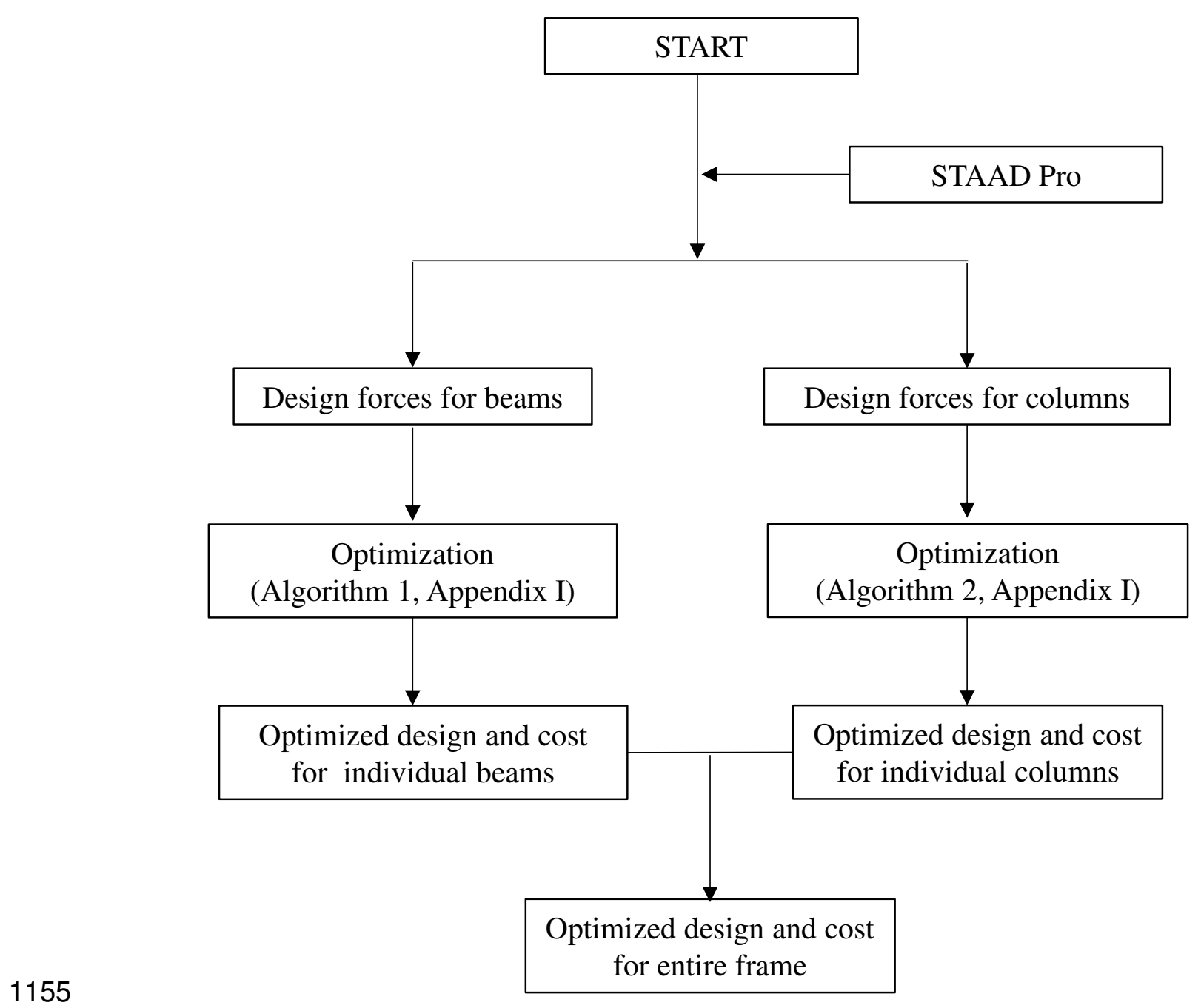

Fig.4. Flowchart for cost optimization of whole frame 
a)

1158

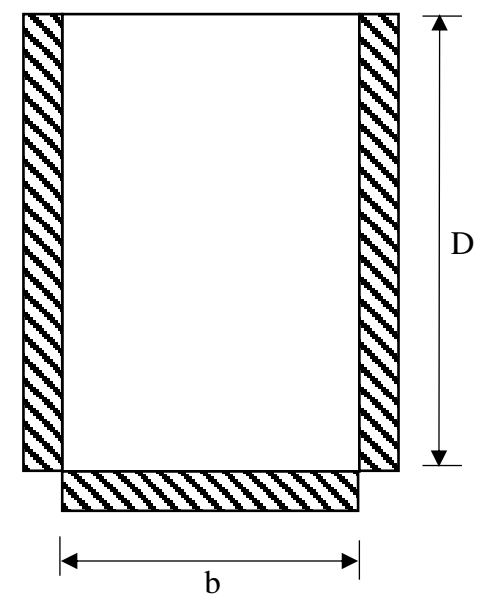

b)

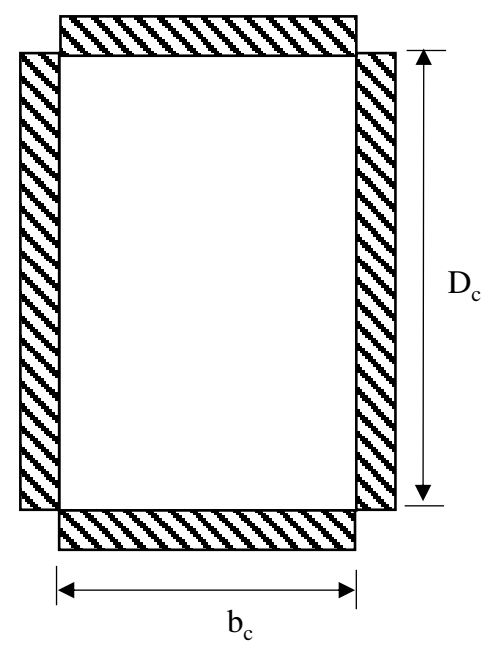

1159

1160

Fig.5.Formwork profile for member cross section: a) Beam b) Column

1161 


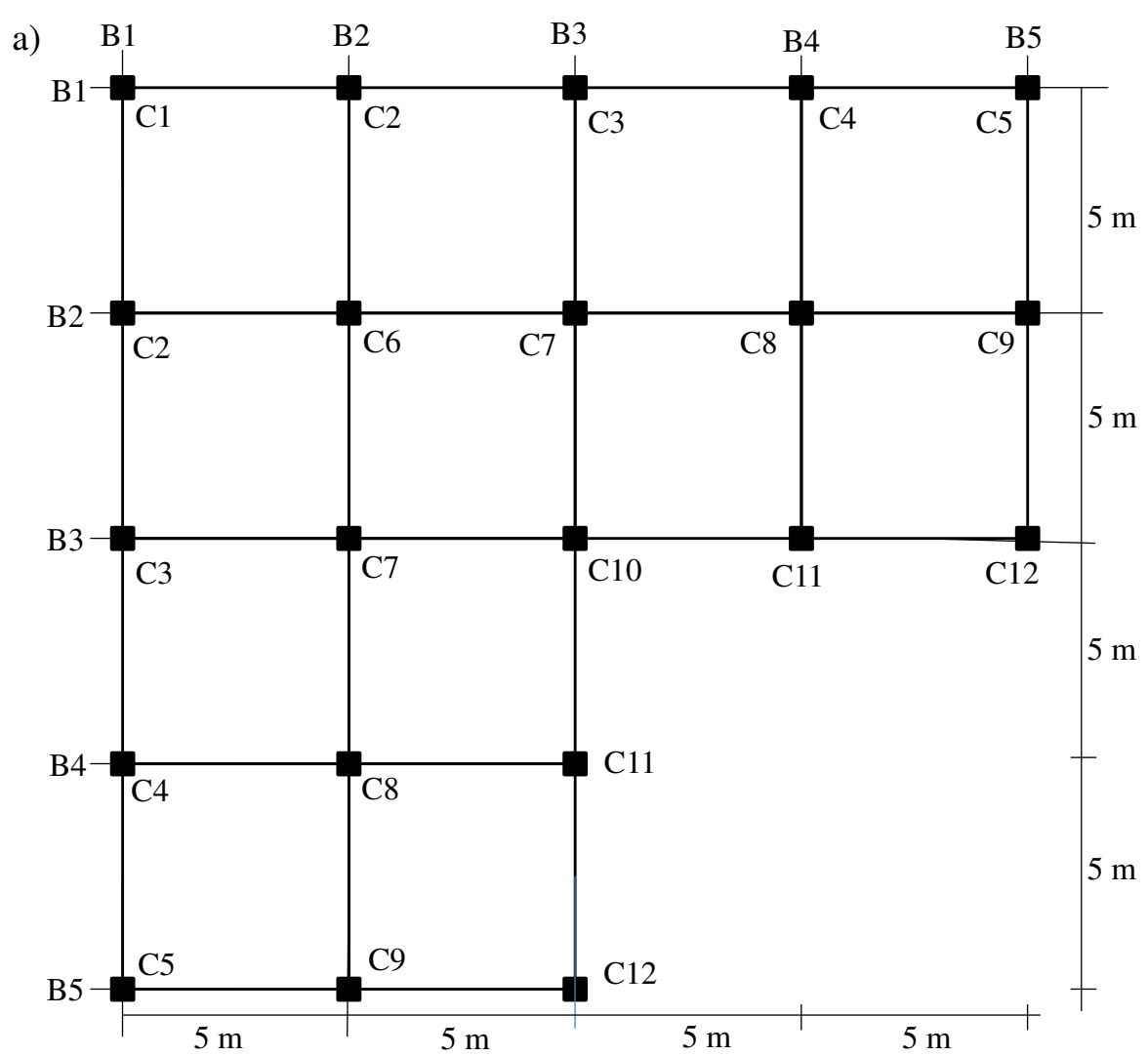

b)

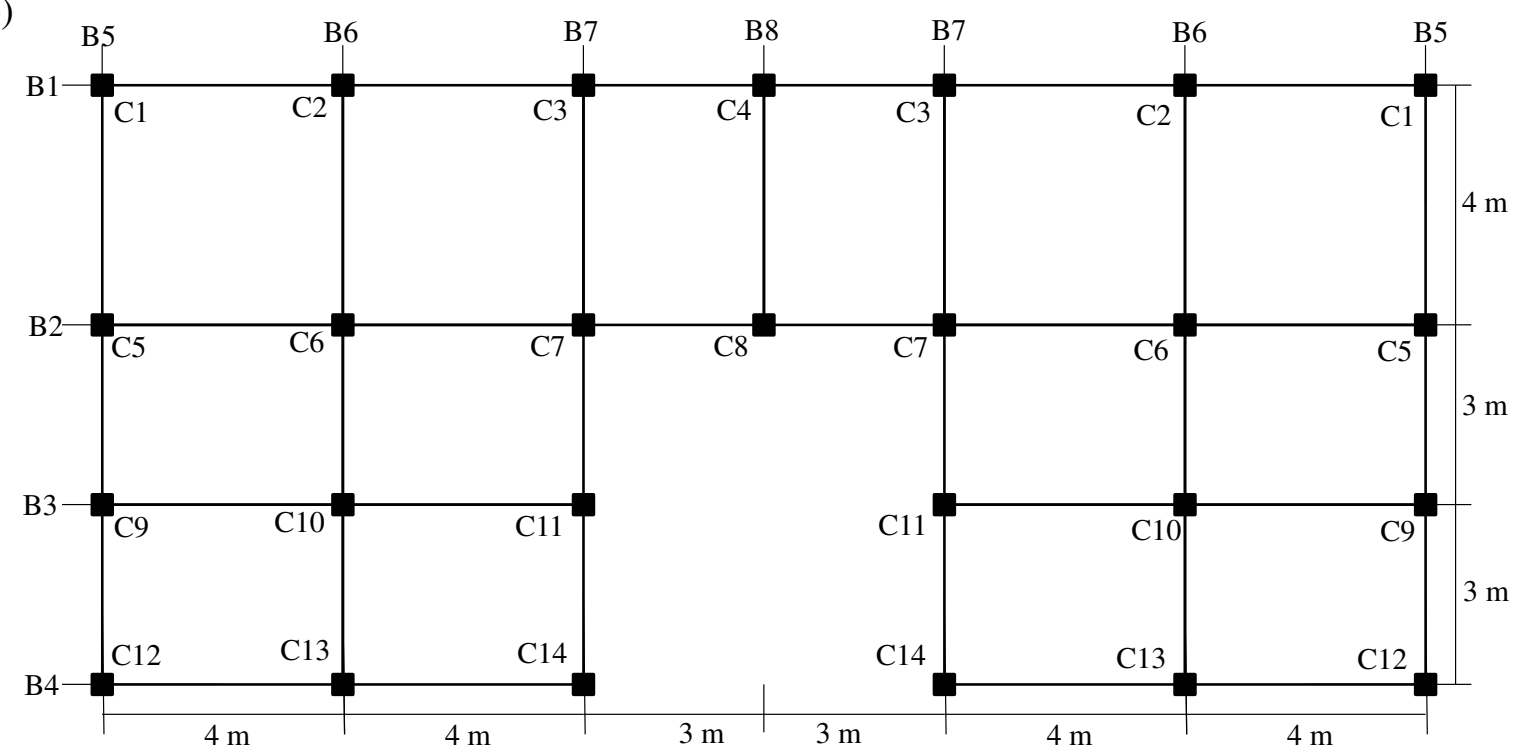

1163 Fig. 6. Typical floor grid plan of the building frames showing beams and column positions a) 
a)

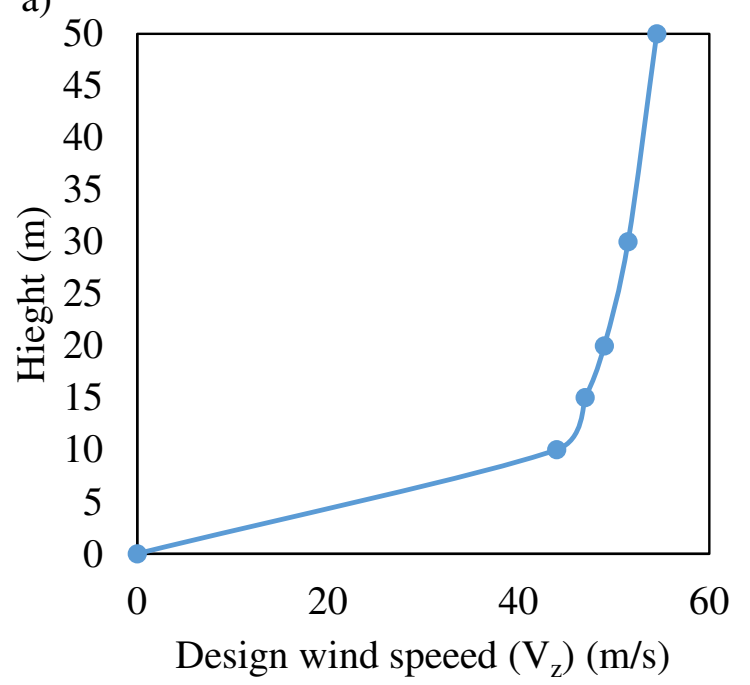

b)

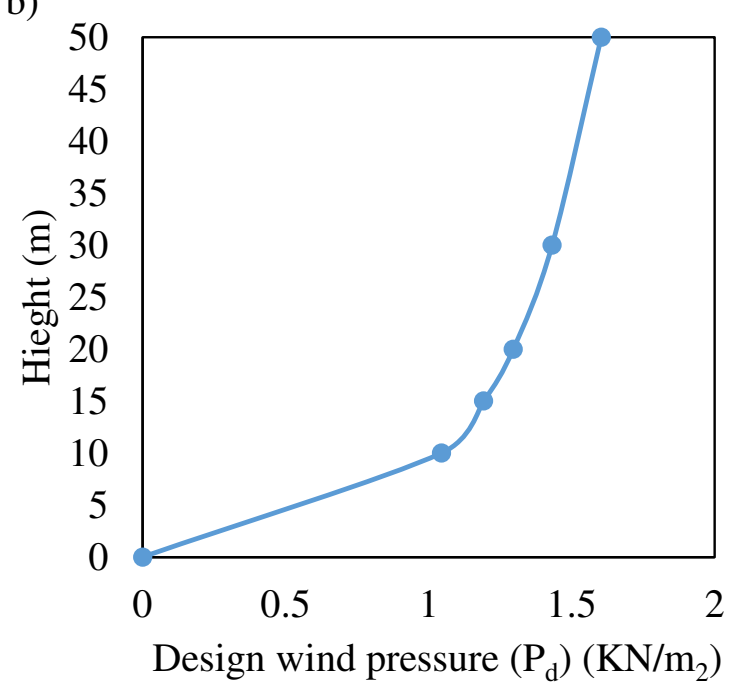

Fig. 7.Wind profile used wind load analysis a) Velocity profile b) Pressure profile 1171 


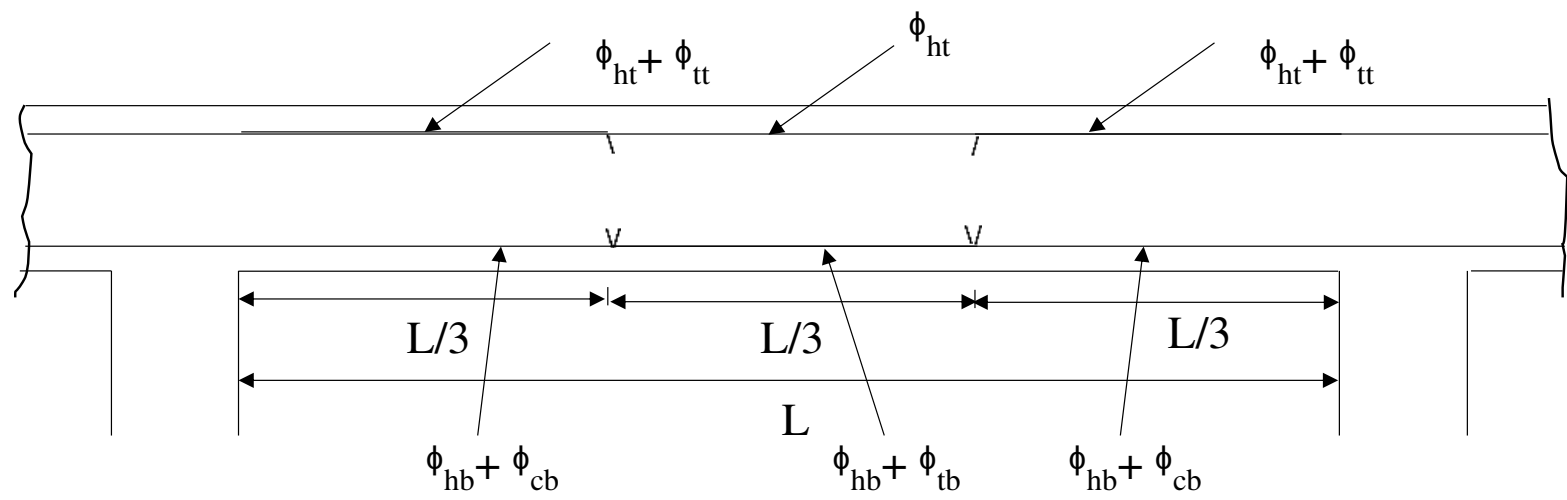

$\phi_{\mathrm{ht}}=$ hanger bars at top, $\phi_{\mathrm{tt}}=$ extra bars at support top due to tension, $\phi_{\mathrm{hb}}=$ hanger bars at bottom, $\phi_{\mathrm{cb}}=$ extra bars at support bottom due to compression, $\phi_{\mathrm{tb}}=$ extra 1175 bars at mid-span bottom due to tension

1177 Fig. 8. Schematic diagram of continuous beam showing the details of curtailments in bars 


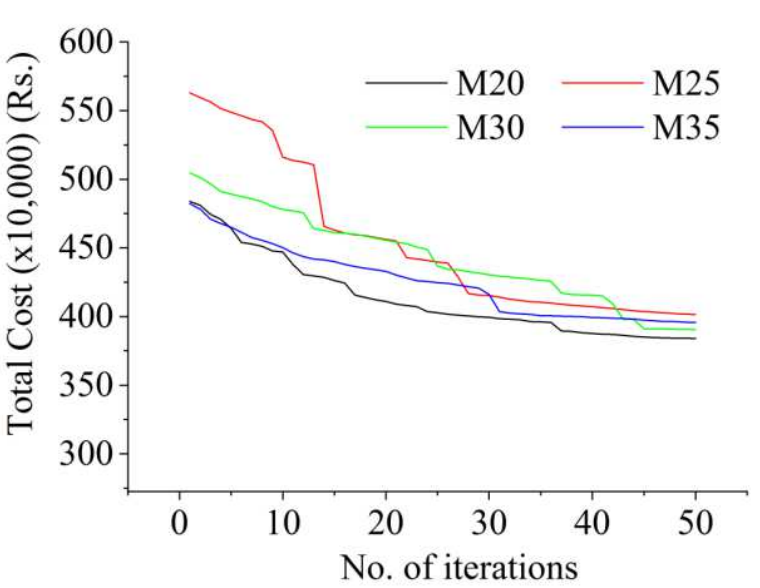

a)

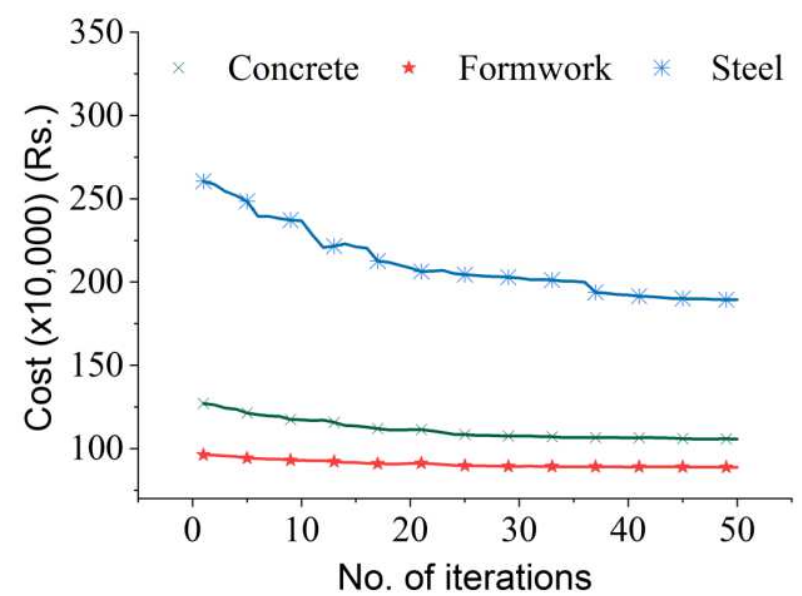

b)

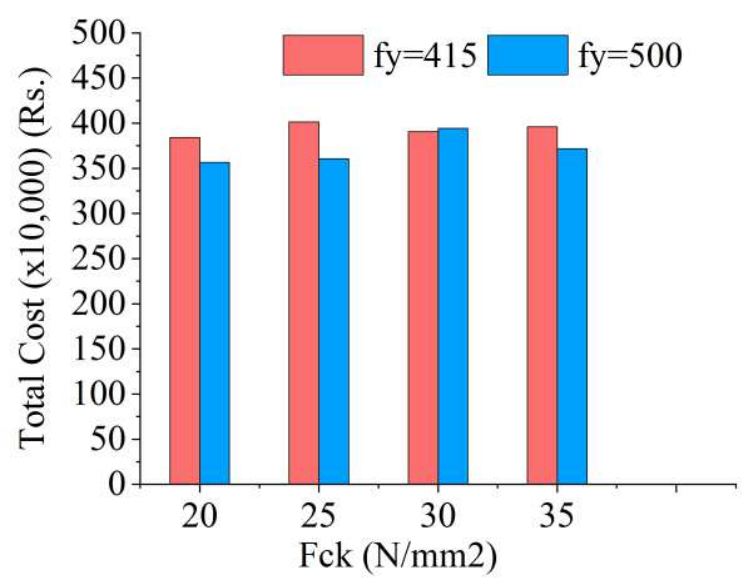

c)

1180 Fig. 9. Design optimization results for L-shaped building frame. (a) convergence curve of 1181 total cost for different grade concrete along with Fe 415 steel.(b) convergence curve for cost 1182 of different parameters for M20 concrete and Fe 415 steel. (c) Variation of total cost for 1183 different concrete and steel grades 


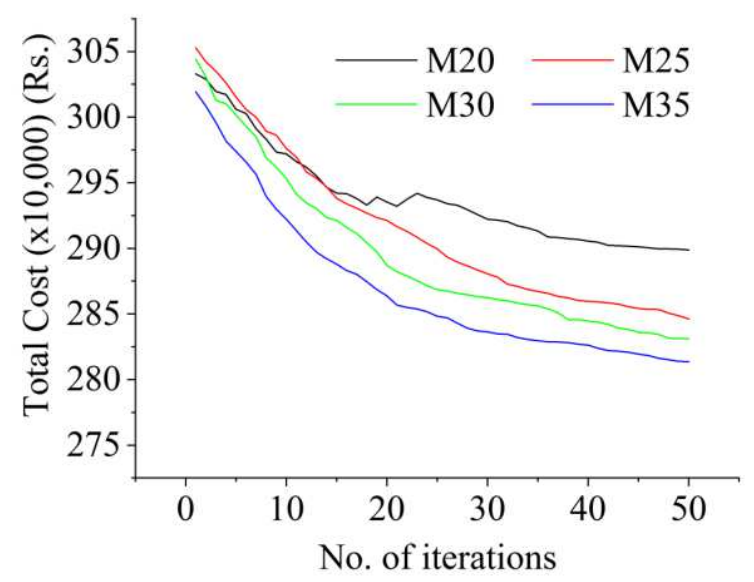

a)

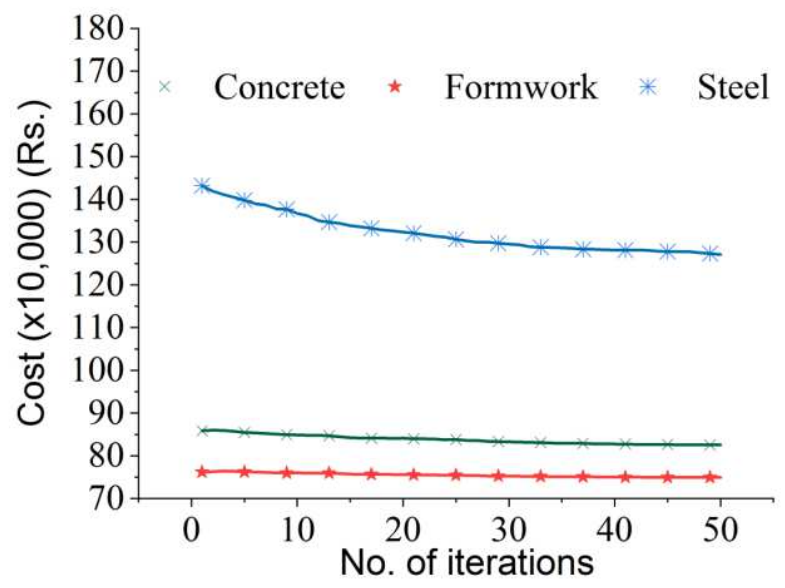

b)

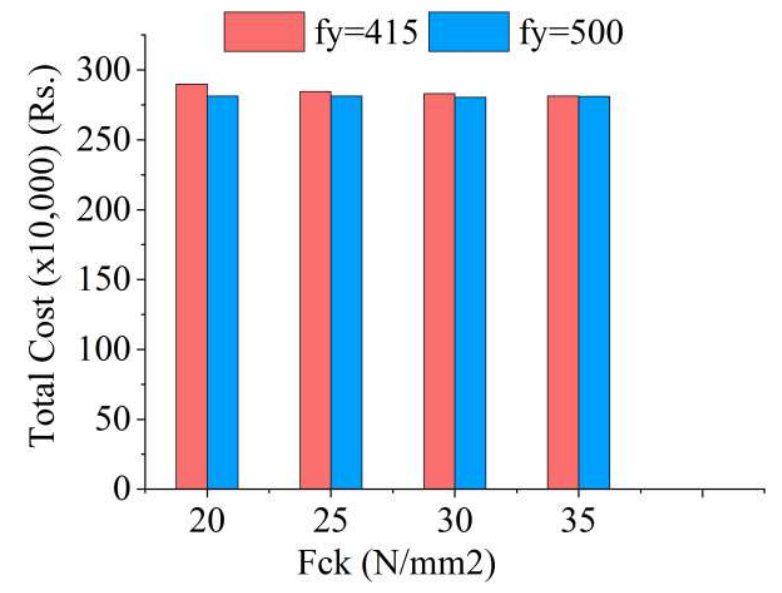

c)

1186 Fig. 10. Design optimization results for U-shaped building frame. (a) convergence curve of 1187 total cost for different grade concrete along with Fe 415 steel. (b) convergence curve for cost 1188 of different parameters for M25 concrete and Fe 415 steel. (c) Variation of total cost for 1189 different concrete and steel grades 


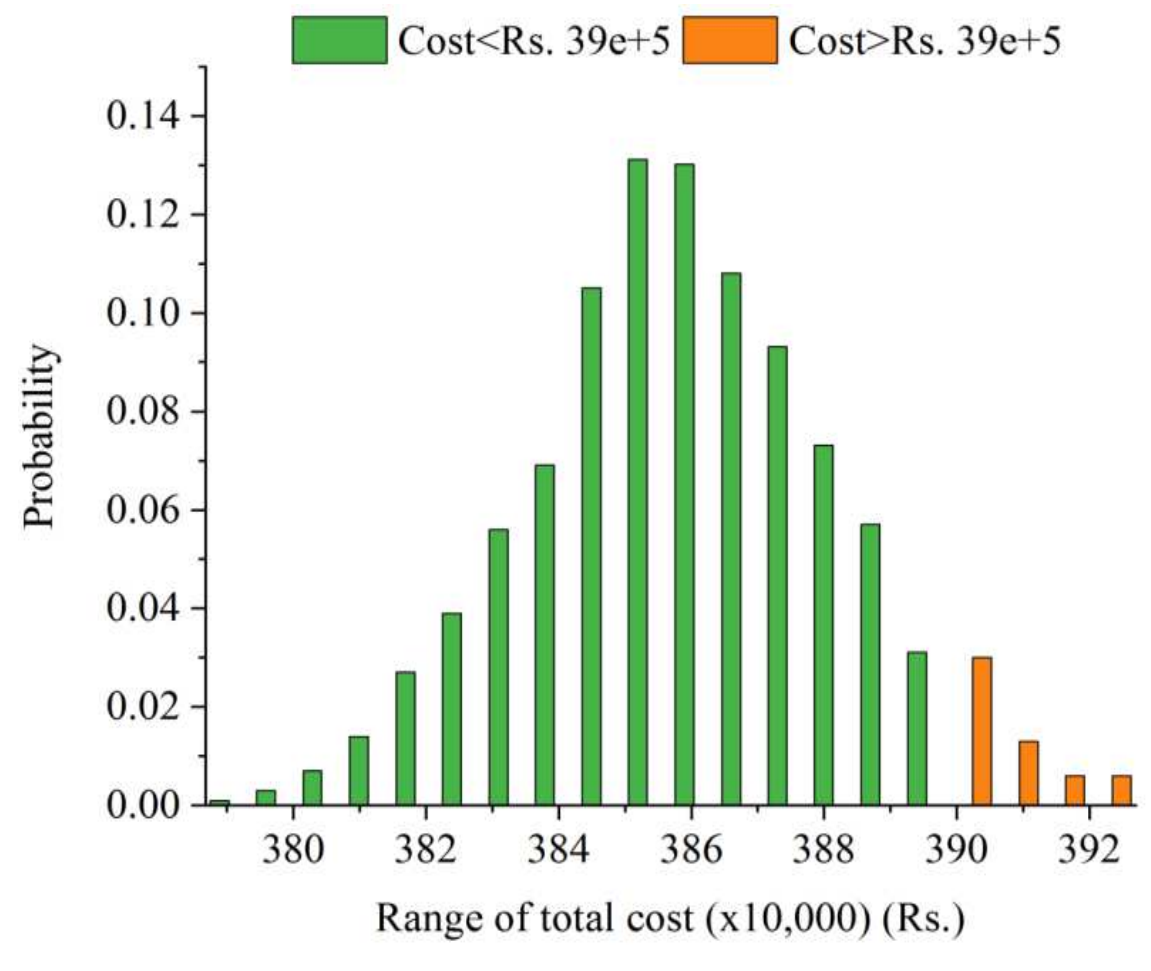

1192

Fig.11. Probability distribution for 5000 simulated solutions (L shaped frame)

1193 


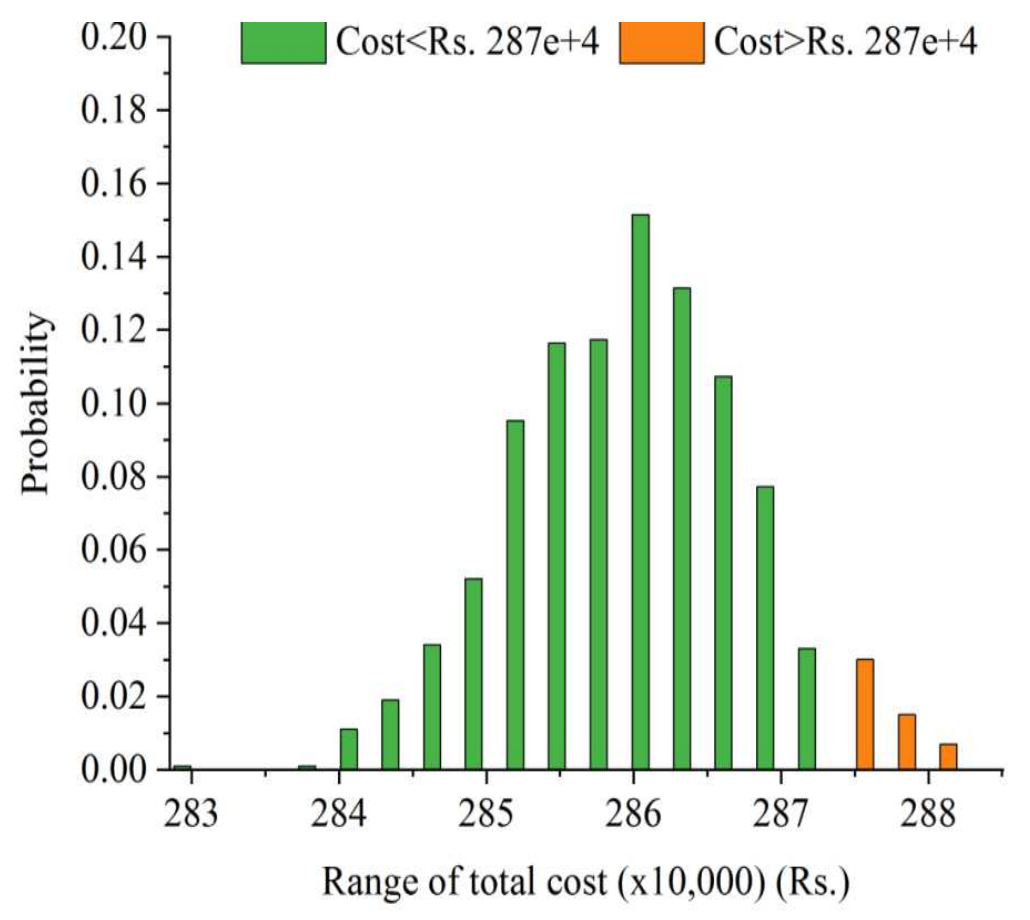

Fig. 12.Probability distribution for 5000 simulated solutions (U shaped frame) 1196 
Figures

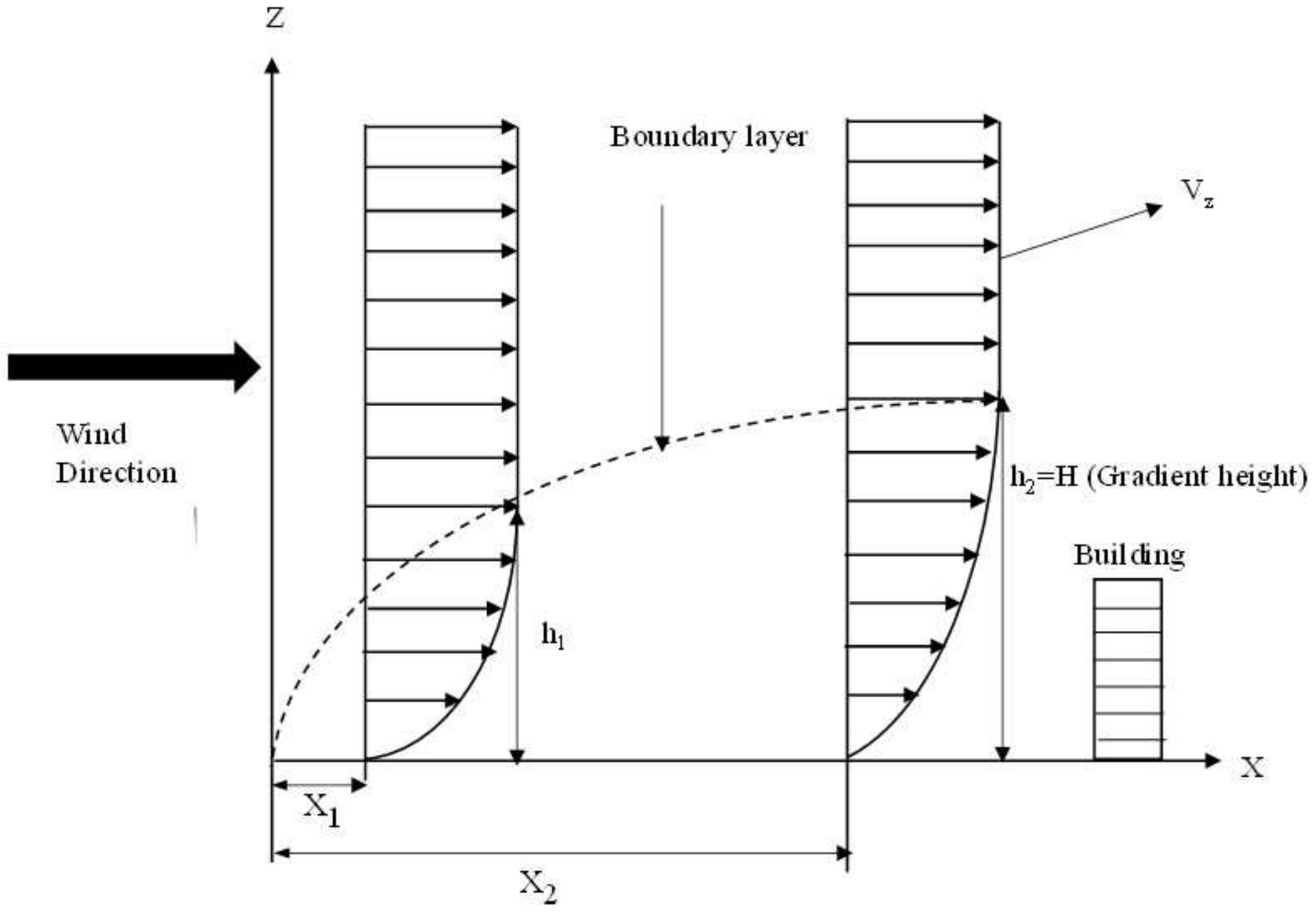

Figure 1

Typical velocity profile of wind moving through a particular terrain $(x 1, x 2=$ fetch length; $h 1, h 2=$ developed height) 


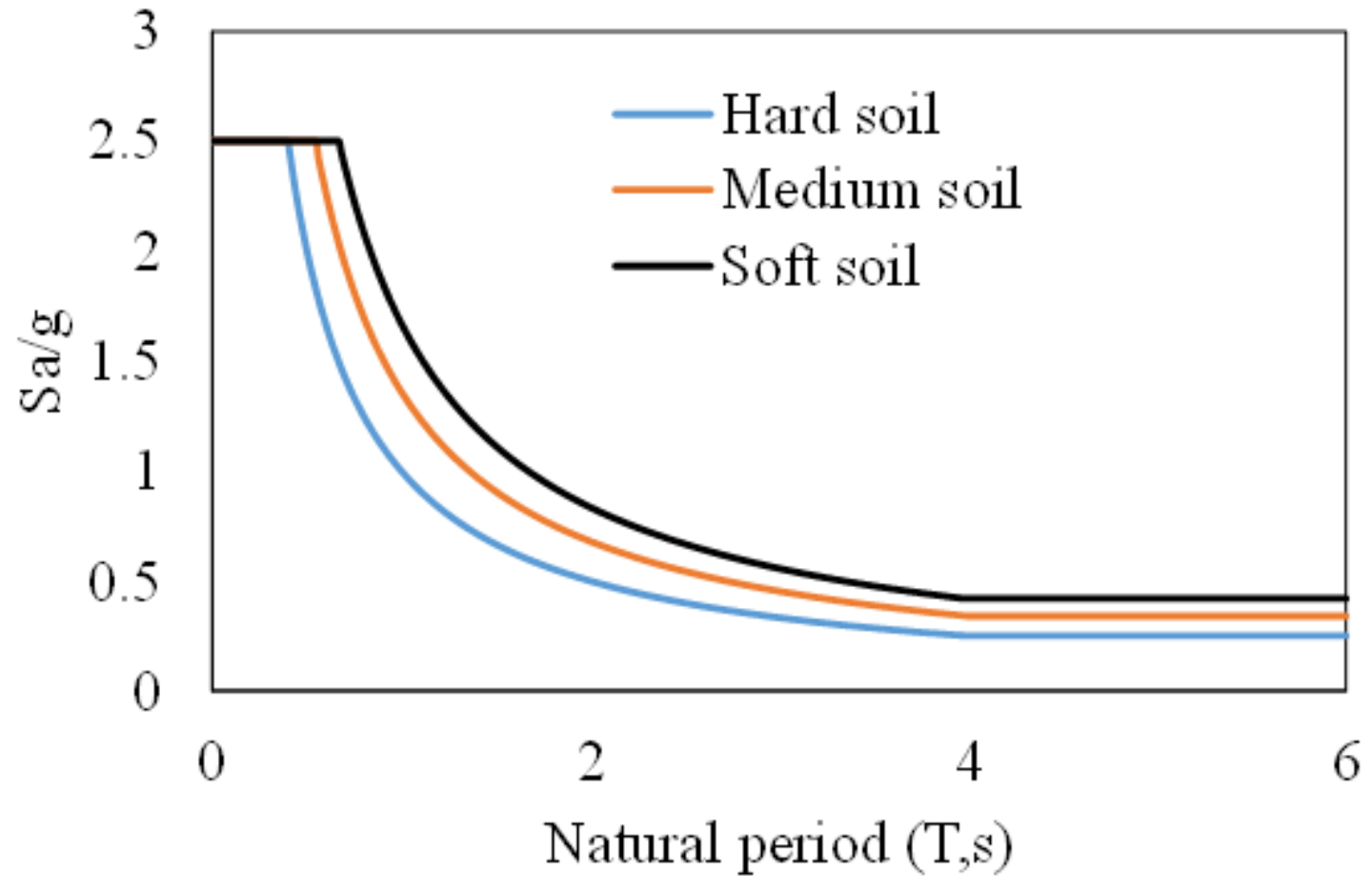

Figure 2

Design acceleration response spectrum of IS 1893-2016(Part-III)[43] 
a)

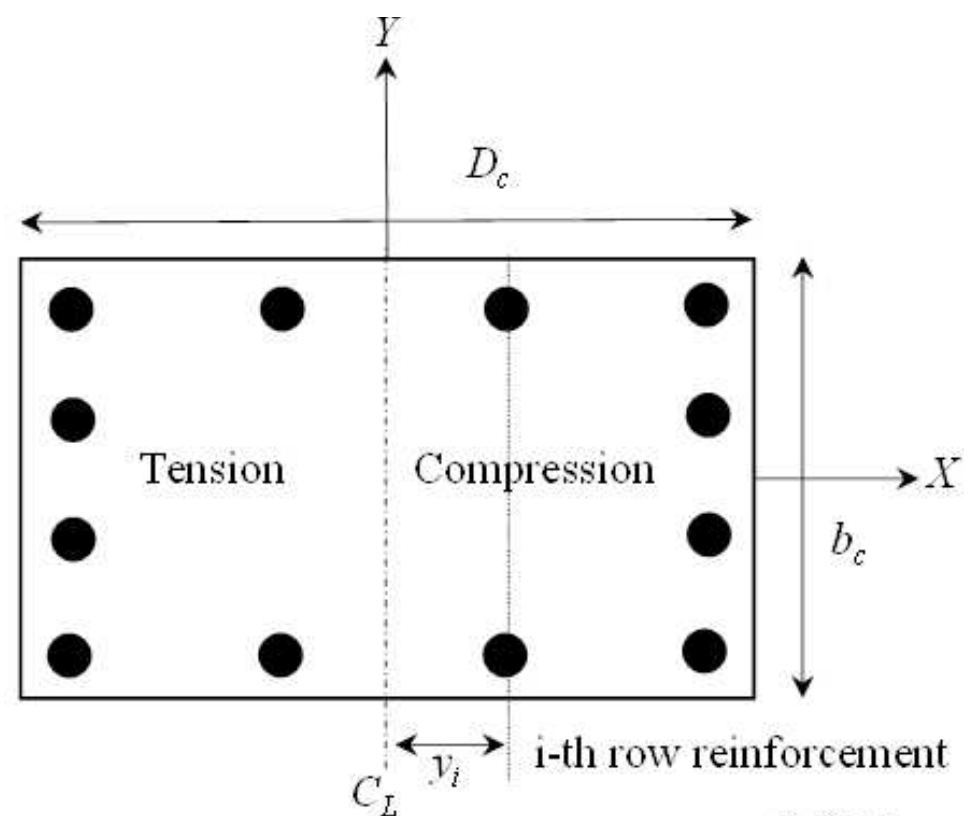

b)

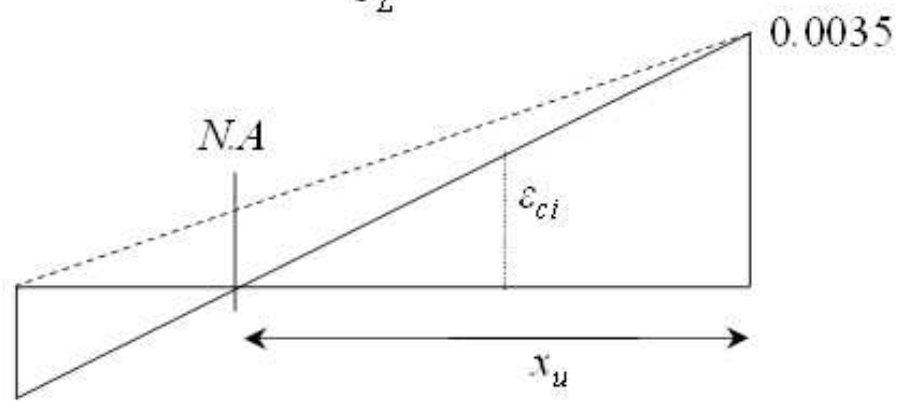

c)

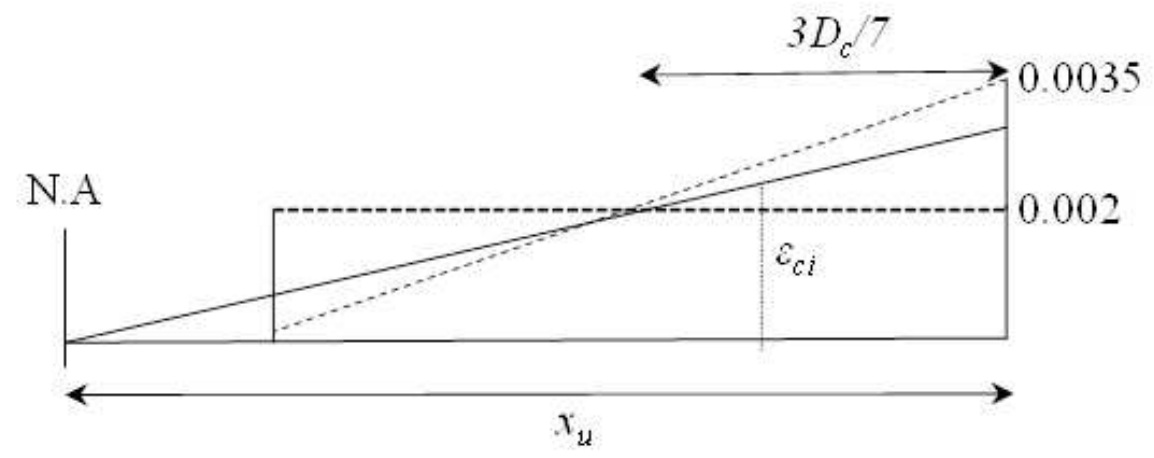

d)

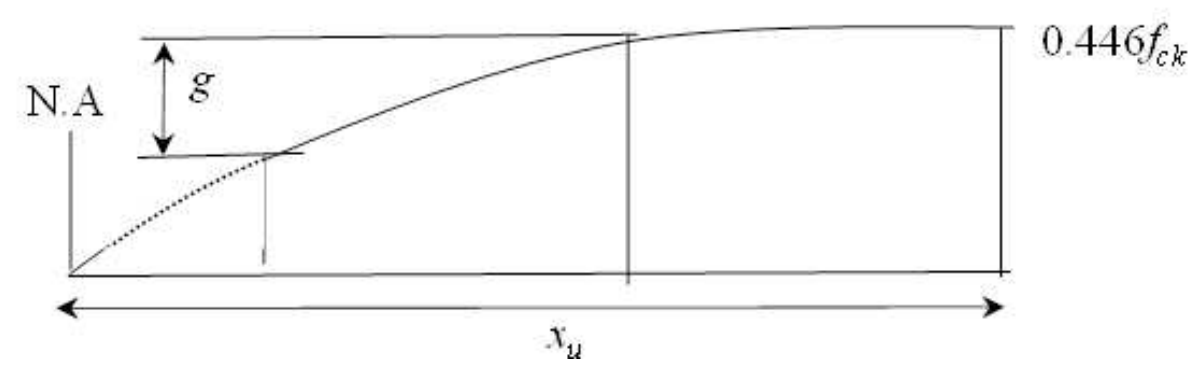

\section{Figure 3}

a) Typical reinforcement detail of column section b) Strain diagram of concrete section when neutral axis lies inside the section c) Strain diagram of concrete section when neutral axis lies outside the section d) Stress diagram of concrete section when neutral axis lies outside the section 


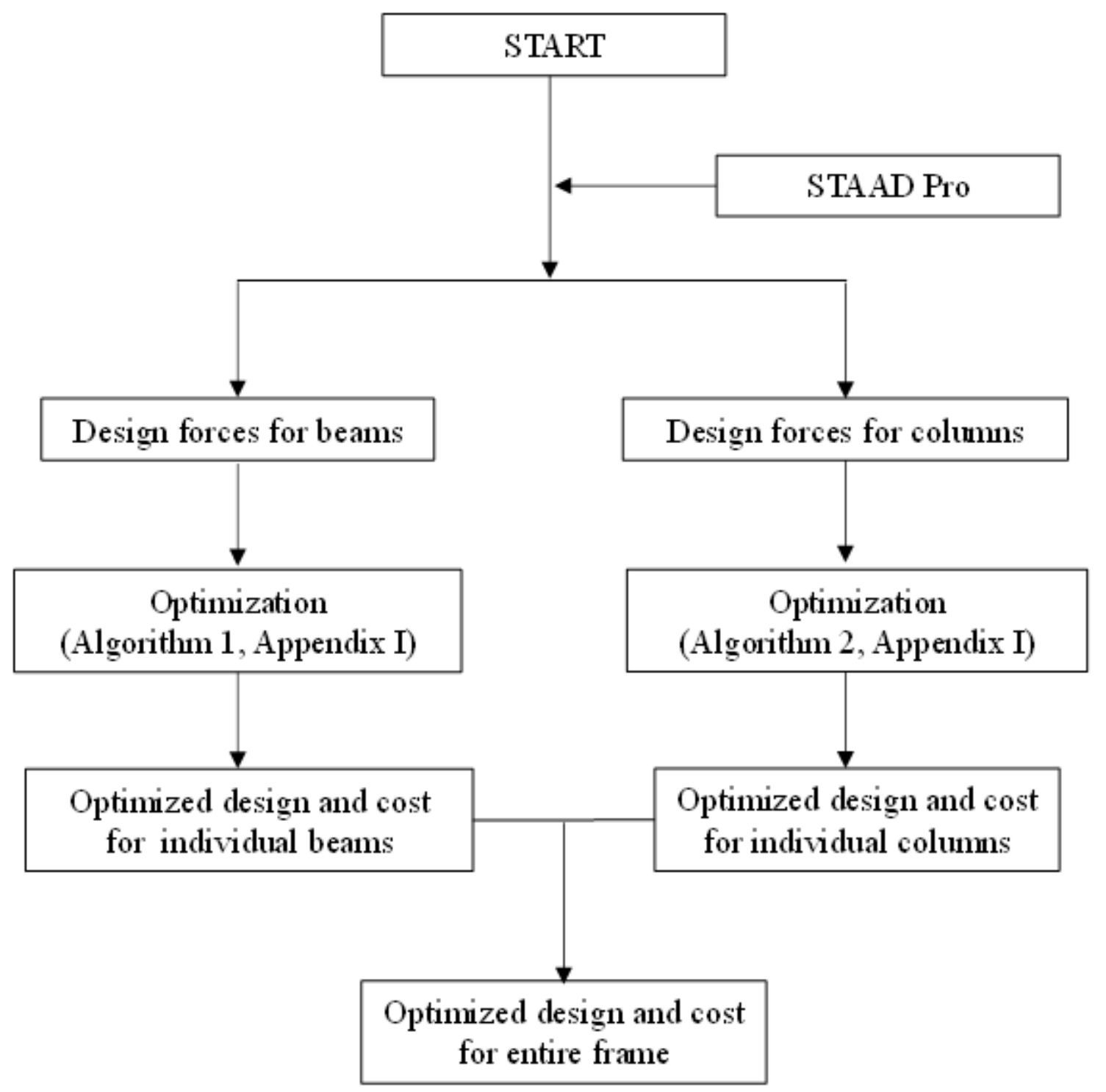

Figure 4

Flowchart for cost optimization of whole frame 
a)

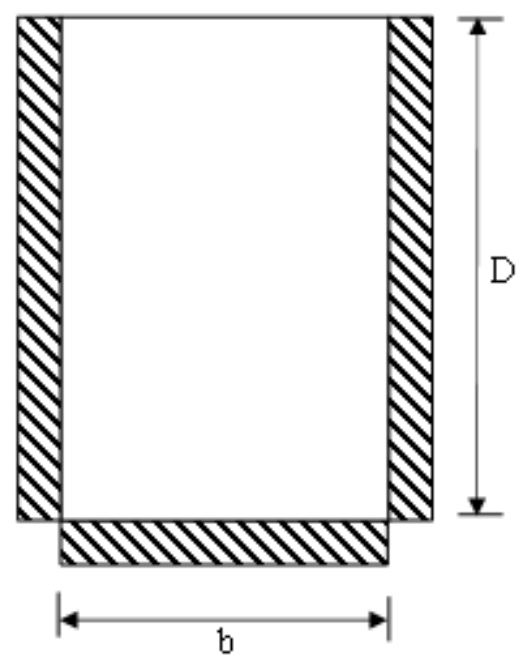

b)

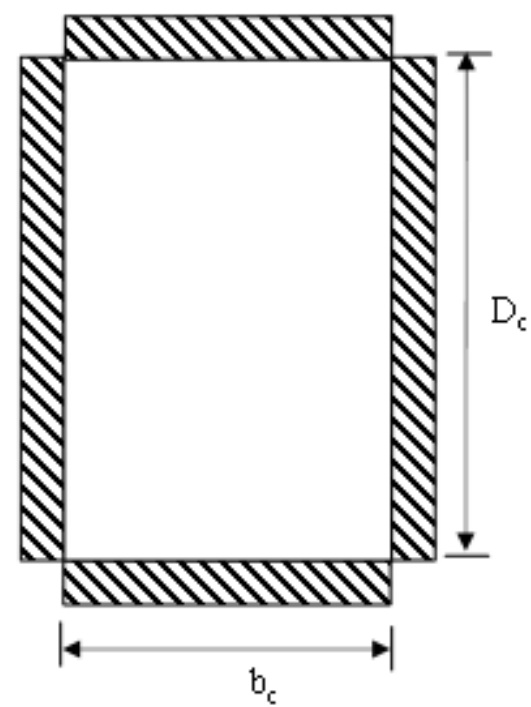

\section{Figure 5}

Formwork profile for member cross section: a) Beam b) Column 


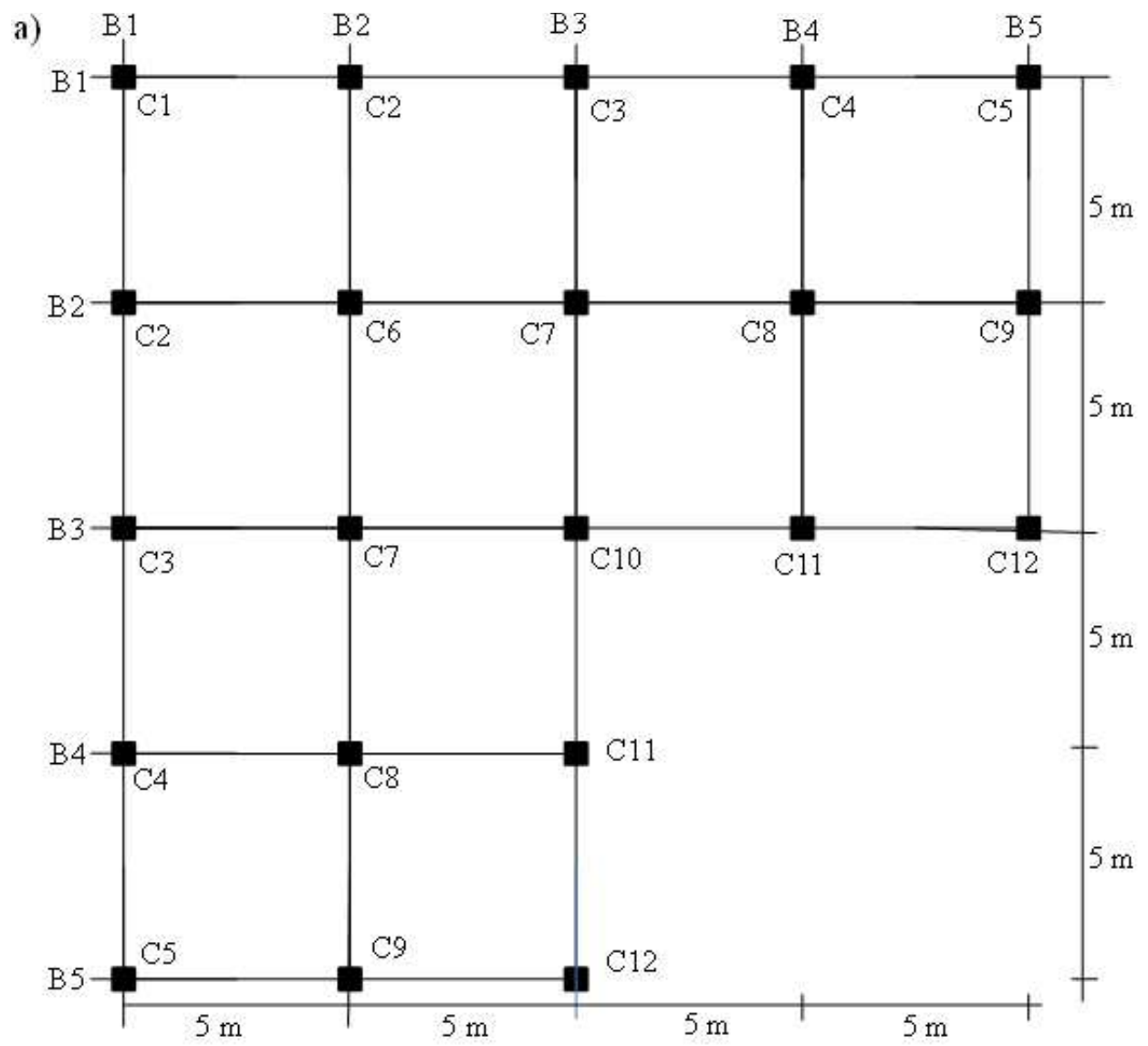

b)

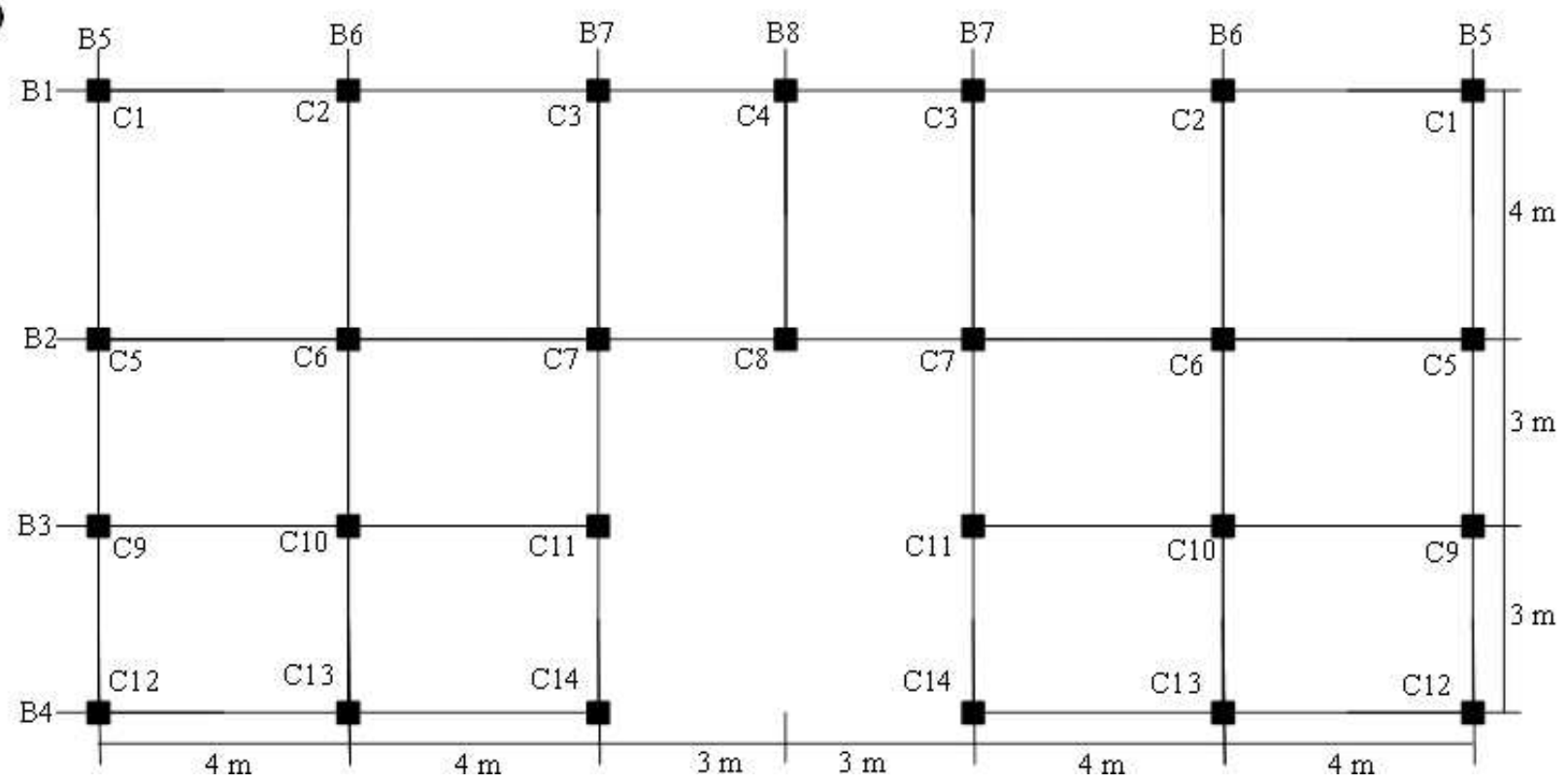

Figure 6

Typical floor grid plan of the building frames showing beams and column positions a) $L$ shaped building b) U shaped building 

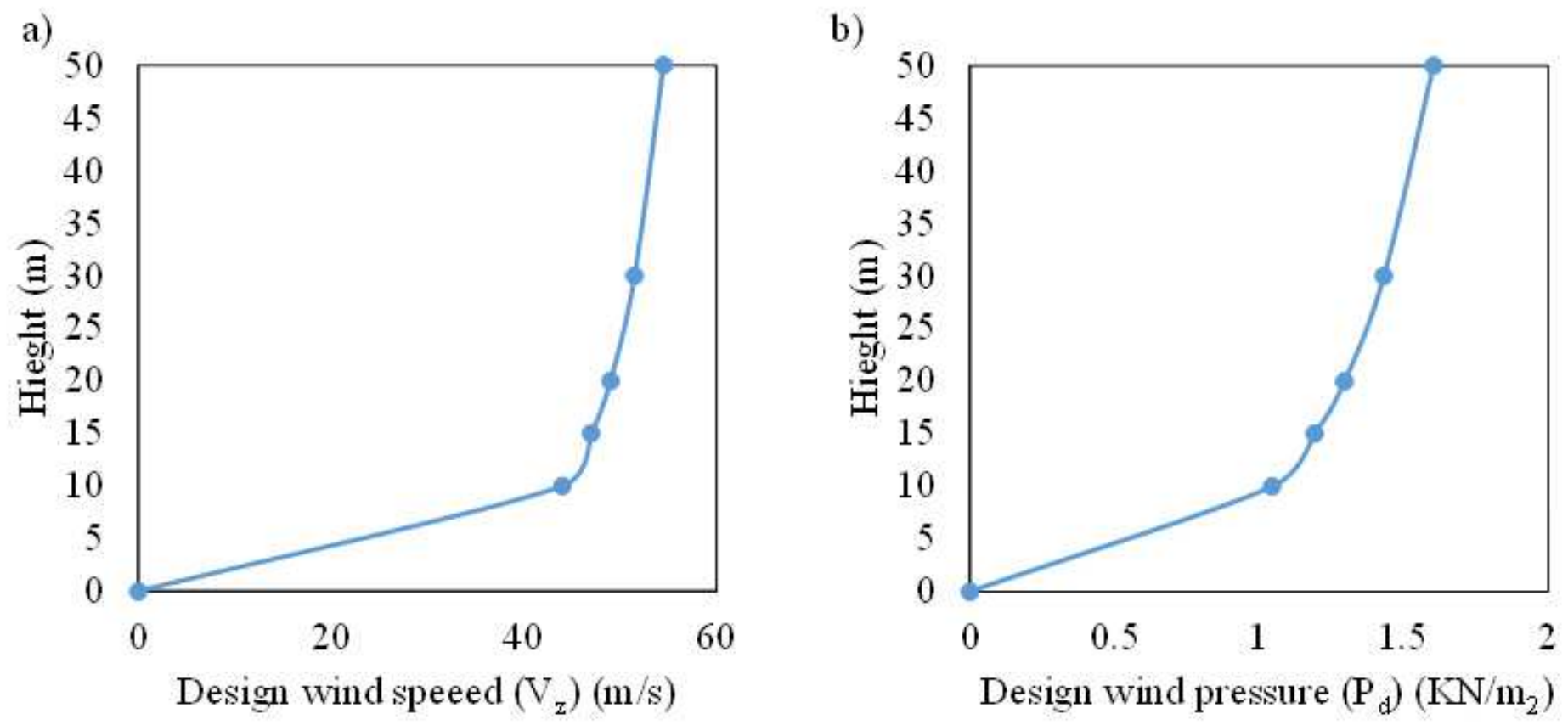

\section{Figure 7}

Wind profile used wind load analysis a) Velocity profile b) Pressure profile

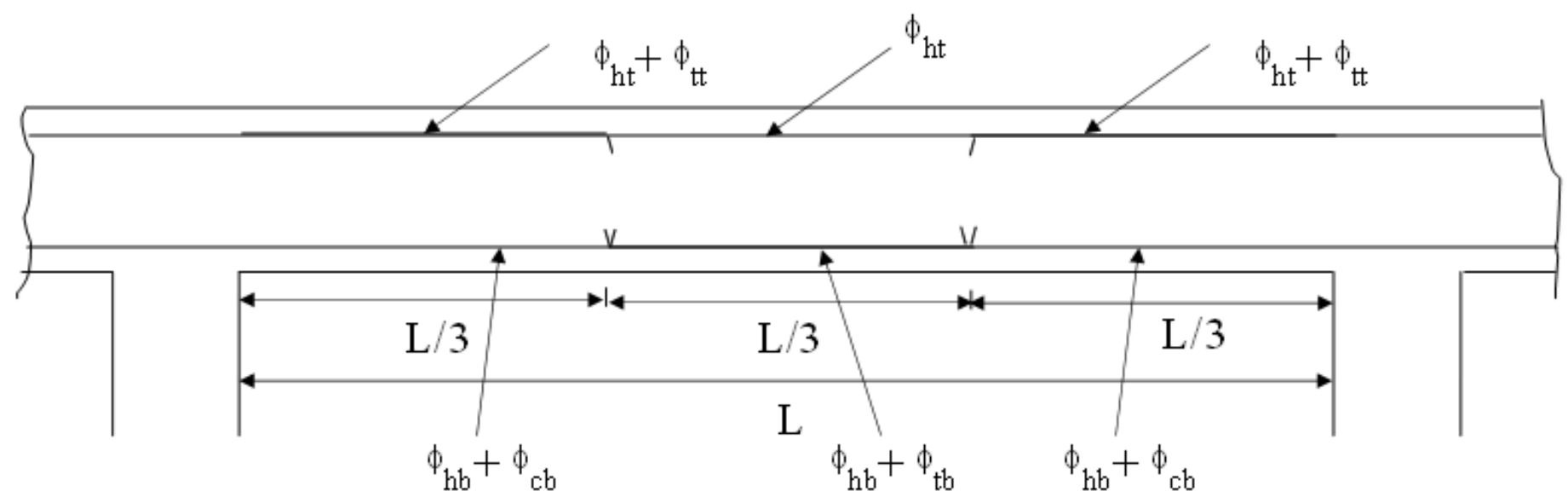

$\phi_{\mathrm{ht}}=$ hanger bars at top, $\phi_{\mathrm{tt}}=$ extra bars at support top due to tension, $\phi_{\mathrm{hb}}=$ hanger bars at bottom, $\phi_{\mathrm{cb}}=$ extra bars at support bottom due to compression, $\phi_{\mathrm{tb}}=$ extra bars at mid-span bottom due to tension

Figure 8

Schematic diagram of continuous beam showing the details of curtailments in bars 


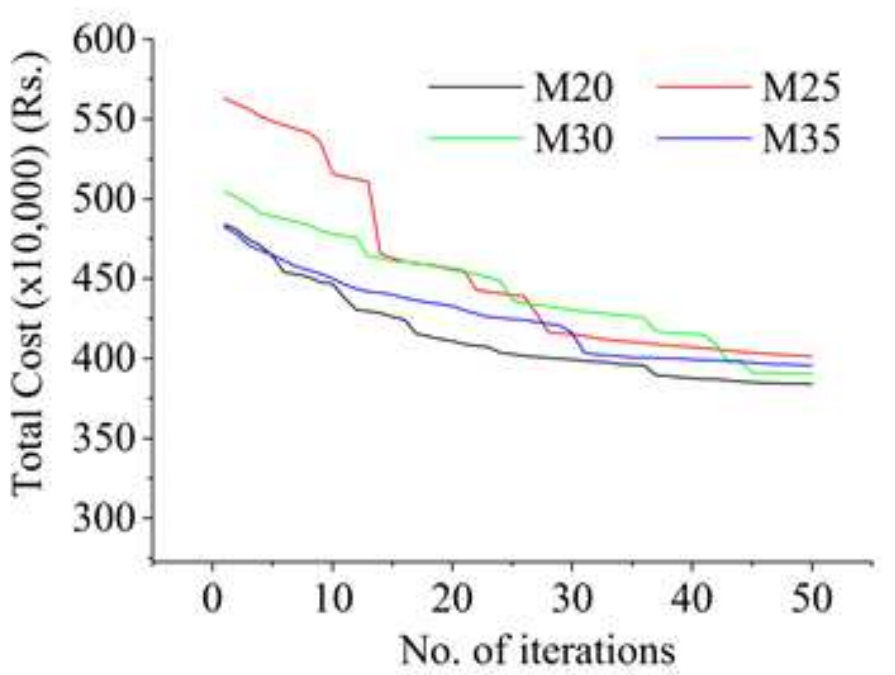

a)

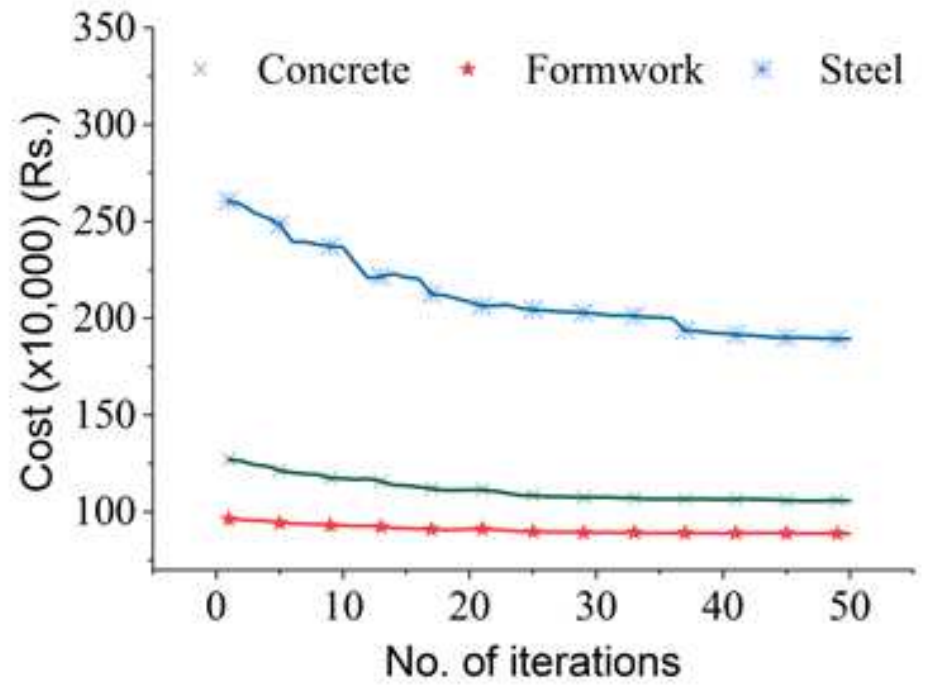

b)

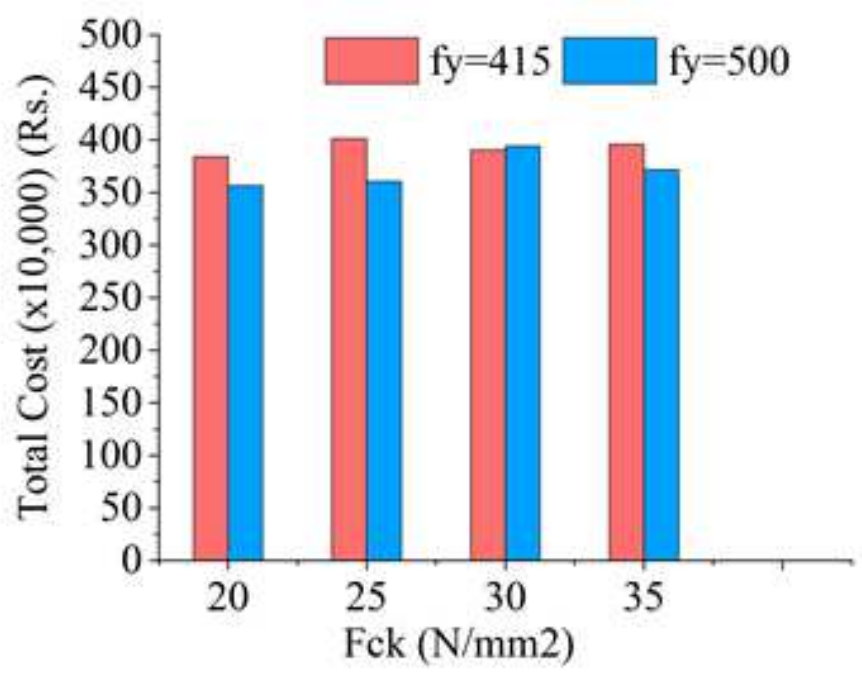

c)

Figure 9

Design optimization results for L-shaped building frame. (a) convergence curve of total cost for different grade concrete along with Fe 415 steel. (b) convergence curve for cost of different parameters for M20 concrete and Fe 415 steel. (c) Variation of total cost for different concrete and steel grades 


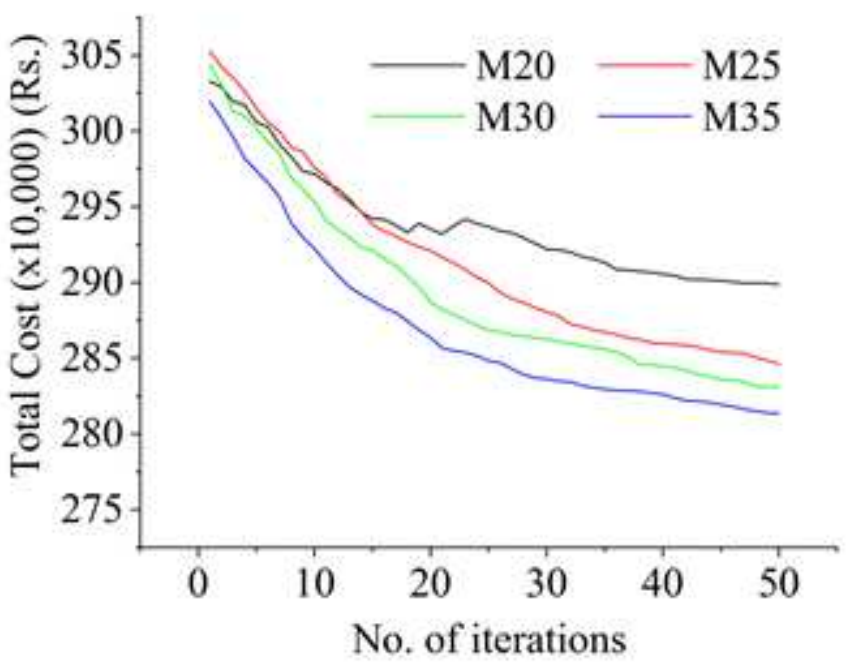

a)

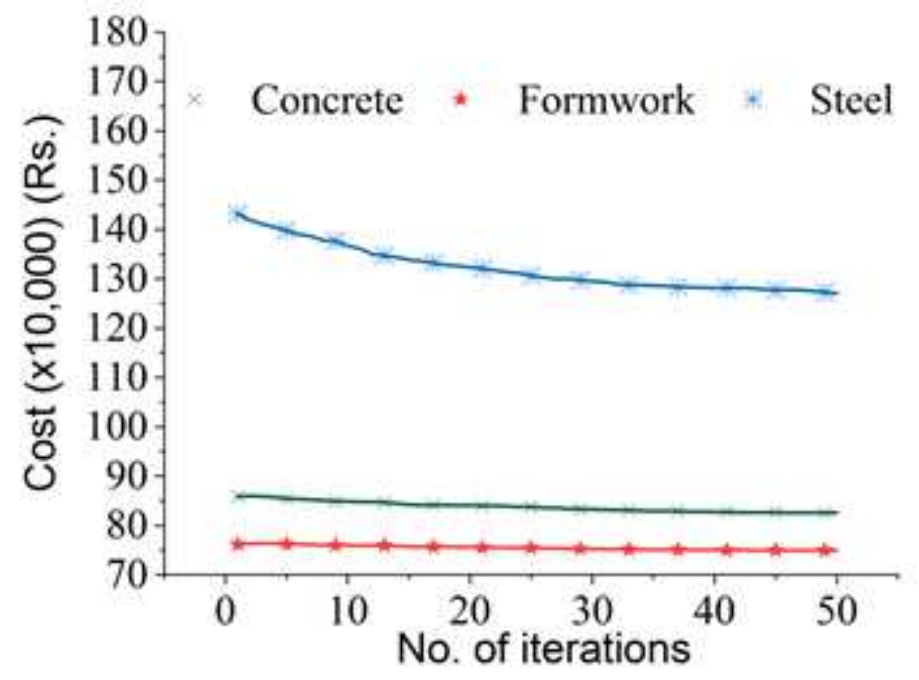

b)

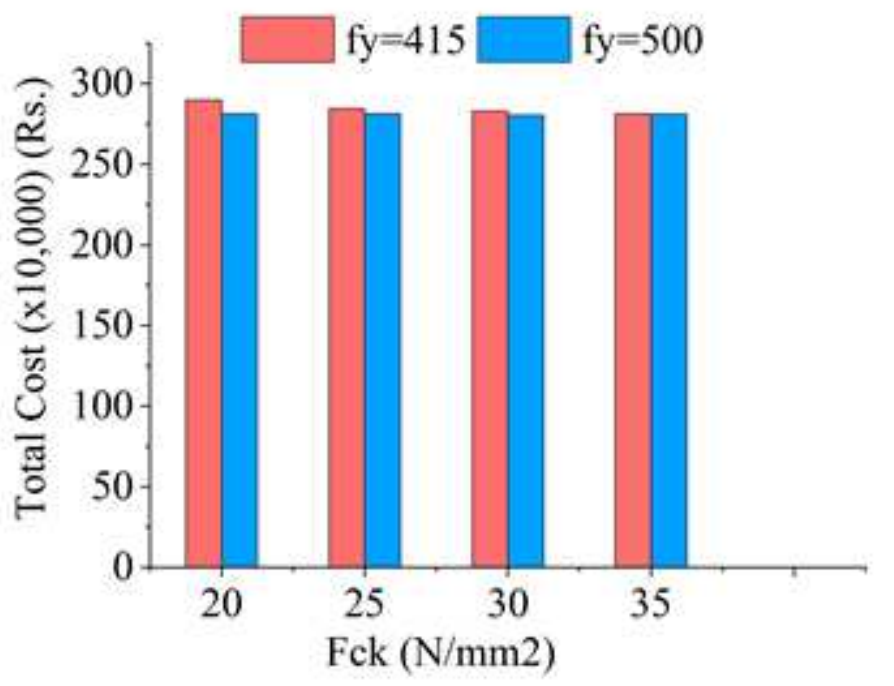

c)

\section{Figure 10}

Design optimization results for U-shaped building frame. (a) convergence curve of total cost for different grade concrete along with Fe 415 steel. (b) convergence curve for cost of different parameters for M25 concrete and Fe 415 steel. (c) Variation of total cost for different concrete and steel grades 


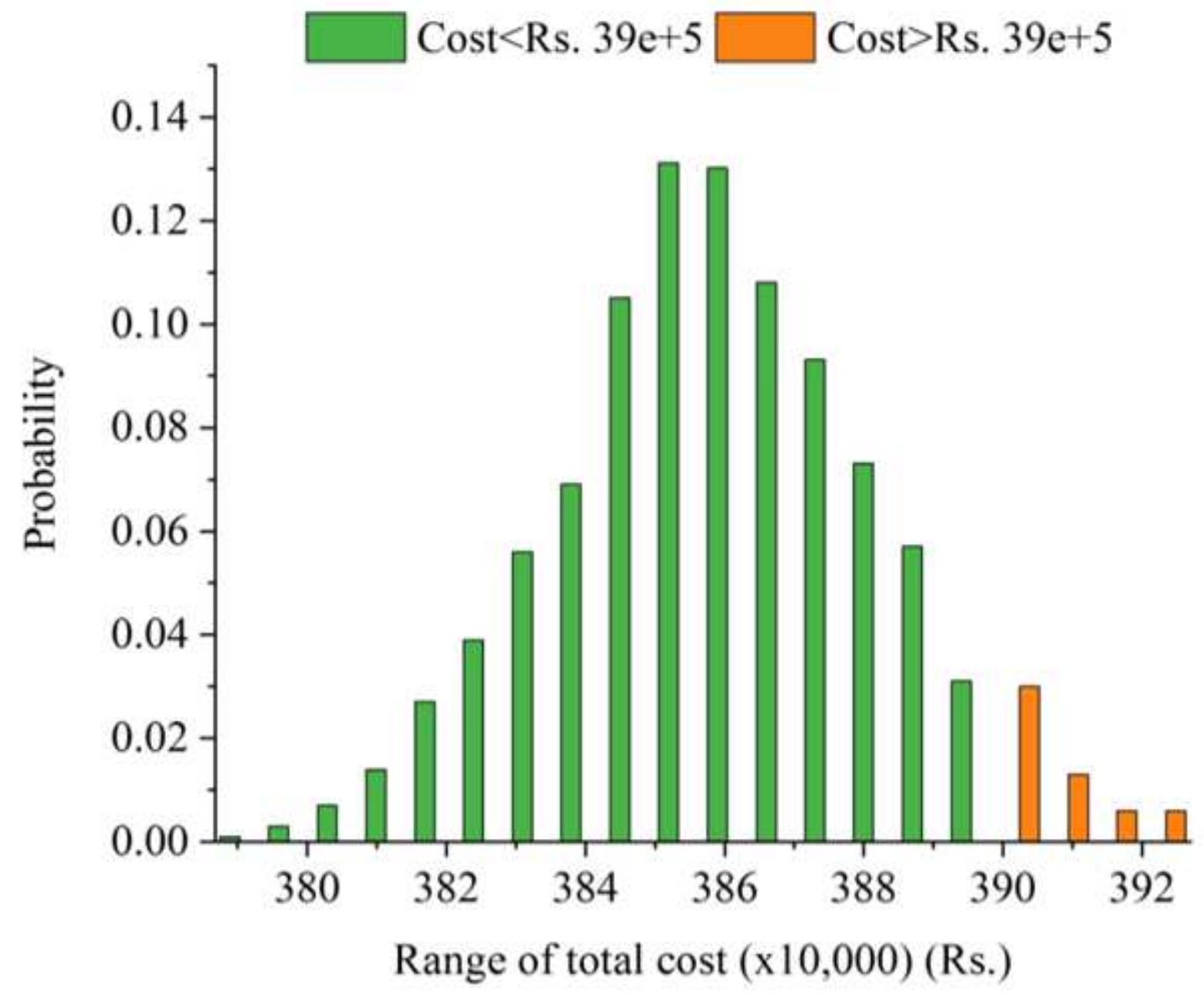

Figure 11

Probability distribution for 5000 simulated solutions ( $L$ shaped frame) 


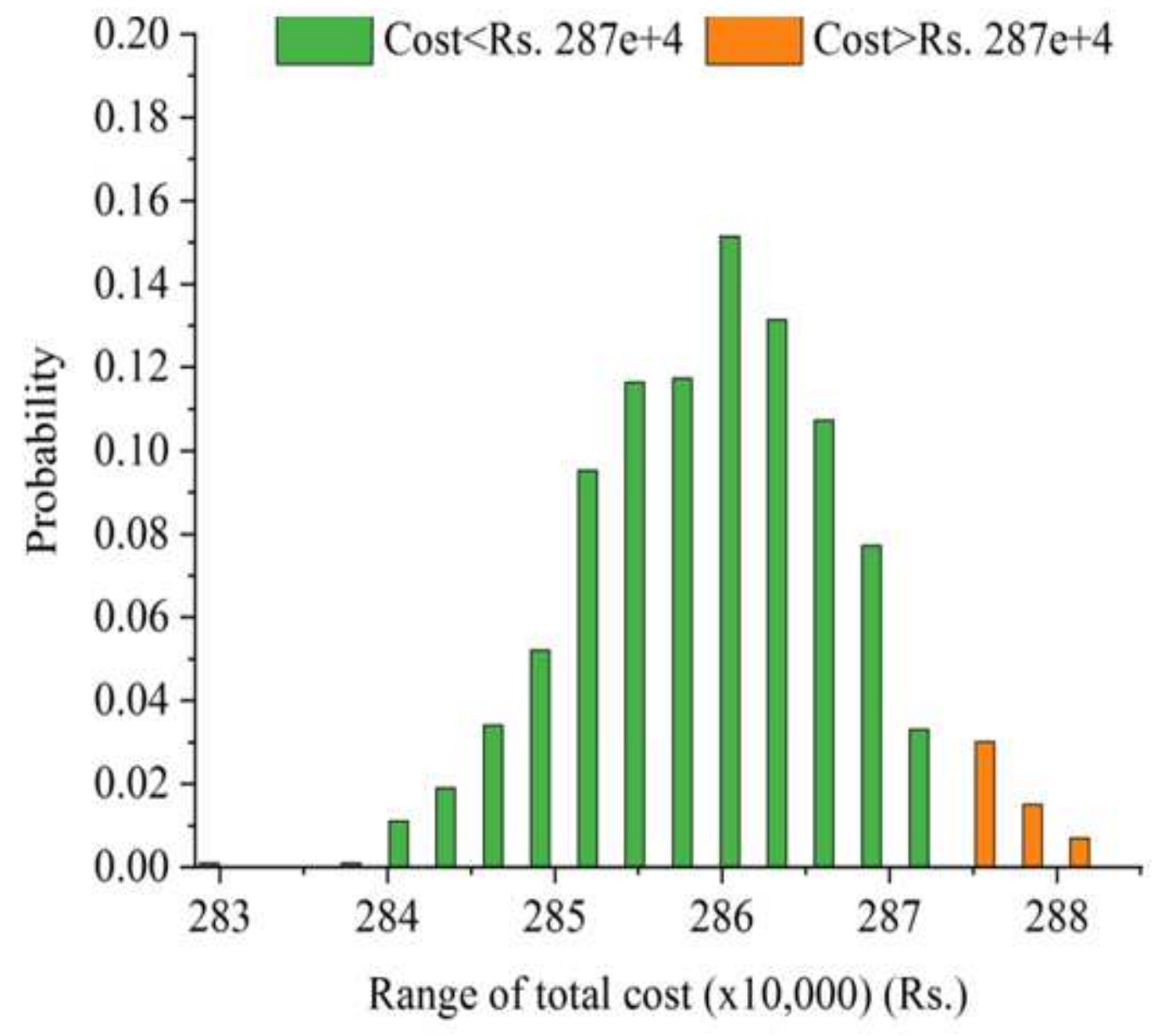

Figure 12

Probability distribution for 5000 simulated solutions (U shaped frame)

\section{Supplementary Files}

This is a list of supplementary files associated with this preprint. Click to download.

- APPENDIX.docx 